STARTING A CAREER IN THE U.S.:

INTERNATIONAL STUDENT PERCEPTIONS

OF THE OPTIONAL PRACTICAL TRAINING EXPERIENCE

A Dissertation
presented to
the Faculty of the Graduate School
at the University of Missouri-Columbia
In Partial Fulfillment
of the Requirements for the Degree
Doctor of Education
br. Paul Watkins, Dissertation Supervisor
December 2018


The undersigned, appointed by the dean of the Graduate School, have examined the dissertation entitled

STARTING A CAREER IN THE U.S.: INTERNATIONAL STUDENT PERCEPTIONS

OF THE OPTIONAL PRACTICAL TRAINING EXPERIENCE

presented by James L. Monahan,

a candidate for the degree of doctor of education,

and hereby certify that, in their opinion, it is worthy of acceptance.

Professor Paul Watkins

Professor Margaret Noe

Professor Melissa Odegard

Professor David Stader 


\section{ACKNOWLEDGEMENTS}

I would like to thank Dr. Paul Watkins, my dissertation supervisor, for helping me complete this project. His encouragement was consistent, and when career and life changes made things complicated, he reminded me of what was important and pointed me to the next step in the process. I am also grateful to the other members of the committee, Dr. Noe, Dr. Odegard, and Dr. Stader who were willing to step in and provide valuable feedback.

I would also like to thank the many individuals working in the field of international education who have provided me with valuable insights and opportunities to learn, but especially Dr. Jeanie Hofer and Dr. Venkat Allada. I appreciate the assistance of my university colleagues who helped me in many ways to complete this dissertation. I am extremely grateful to the international students who shared their stories with me for this study, and to all of the international students I have worked with through the years. You have taught me a great deal about the world and the generosity of the people found in it.

A special thank you to Jim Peppler for your extra support and carefully timed encouragement during this entire process. Thanks to my siblings and extended family; I am lucky to have such amazing people in my life. Finally, I want to thank my parents who have always encouraged me during my educational journey. Dad, you are my role model. Thank you for demonstrating how to treat all people with respect and kindness, and instilling in your children the value of knowledge and education. Mom, as the first immigrant that I ever met, you have inspired my life's work, taught me that thinking differently can be a source of strength, and always pushed me to reach higher. I am sincerely grateful. 


\section{TABLE OF CONTENTS}

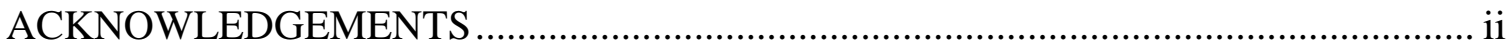

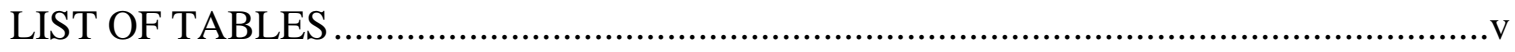

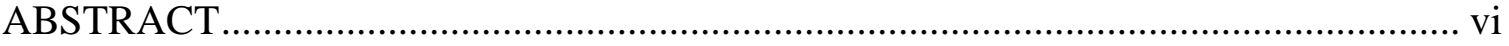

Chapter

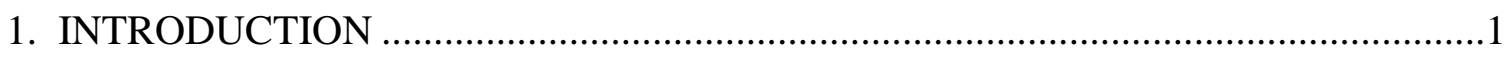

Purpose of the Study ...............................................................................

Description of the Theoretical Framework .......................................................

Rationale for Using Qualitative Research Methods.........................................8

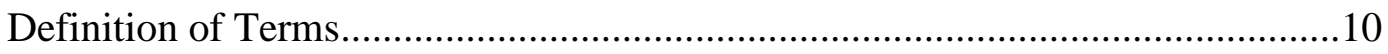

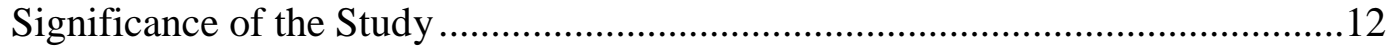

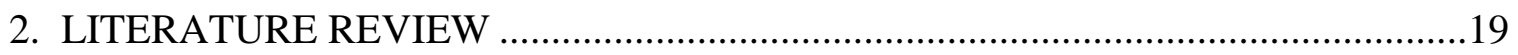

Common Issues Faced by International Students .........................................19

Advising and Mentoring ......................................................................... 24

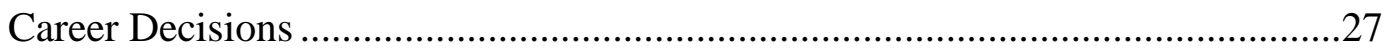

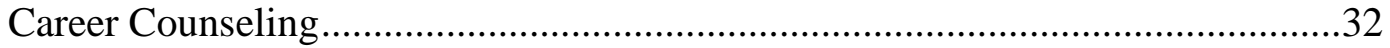

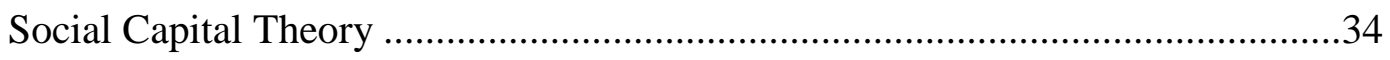

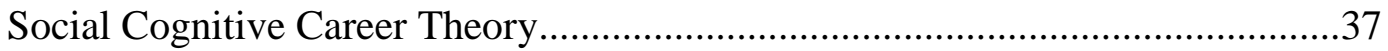

Discussion of Immigration Policies Impacting International Students................40

3. RESEARCH METHODS AND DATA COLLECTION ……………………….........46

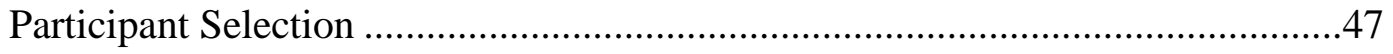

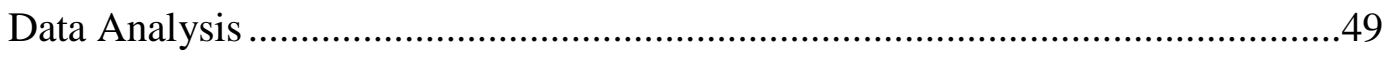

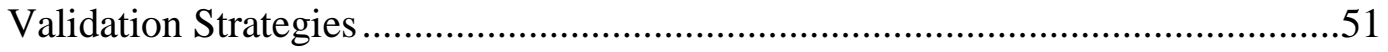




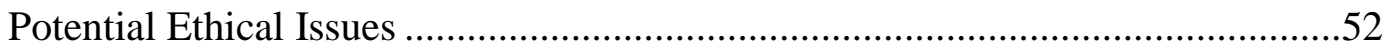

Role and Background of the Researcher...................................................53

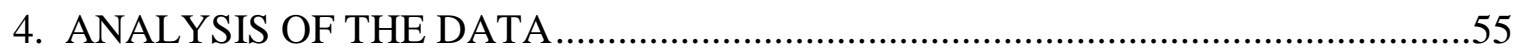

Discussion of the Data Collection Process ..........................................................56

Observations during the Data Collection Process............................................59

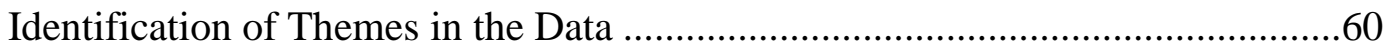

Theme 1: Opportunities Provided by the OPT Program..................................62

Theme 2: Problems and Limitations of the OPT regulations ............................67

Theme 3: University Role in Preparation for Employment ..............................76

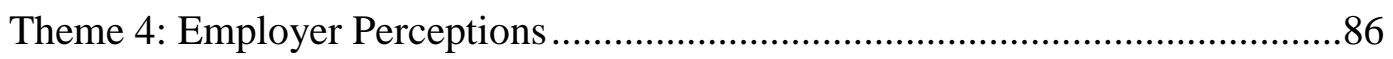

Theme 5: Cultural and Personal Issues Relating to Career Development ............91

5. DISCUSSION, CONCLUSIONS, AND RECOMMENDATIONS .........................102

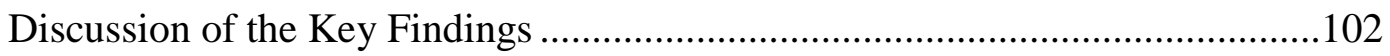

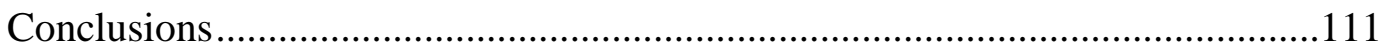

Limitations of the Study.................................................................... 115

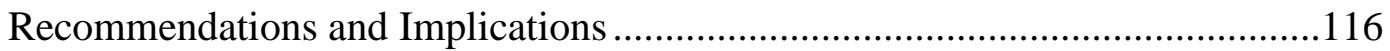

Suggestions for Further Study ..........................................................119

APPENDIX

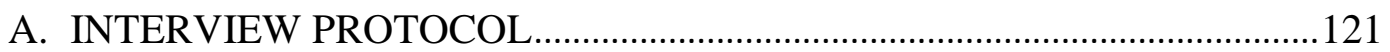

B. COMPLETE TABLE 1 WITH INDIVIDUAL STUDENT RESPONSES ...123

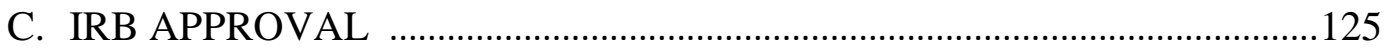

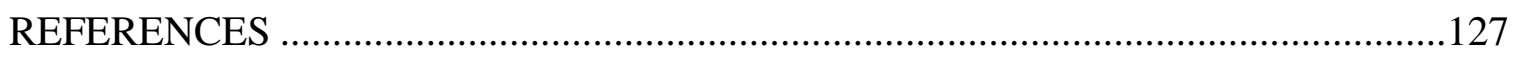

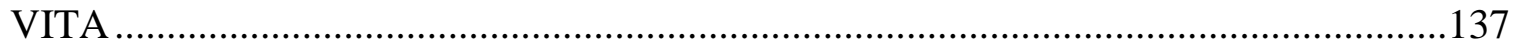




\section{LIST OF TABLES}

Table Page

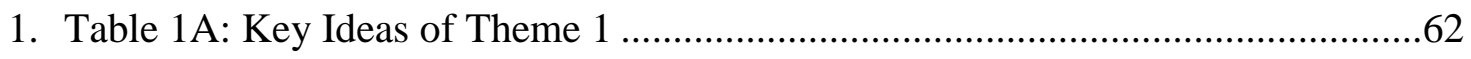

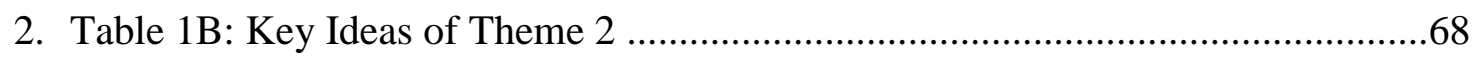

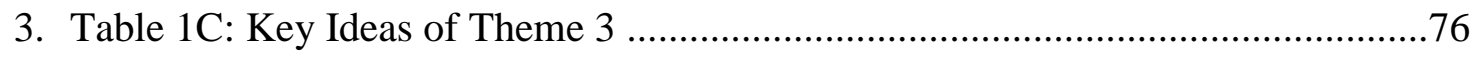

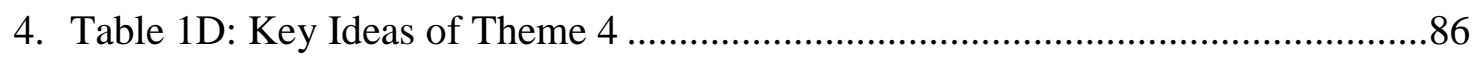

5. Table 1E: Key Ideas of Theme 5 .................................................................... 91

6. Table 2: Key Findings Related to the Research Questions .................................103

7. Appendix B: Complete Table 1 with Individual Student Responses ....................123 


\title{
STARTING A CAREER IN THE U.S.: INTERNATIONAL STUDENT PERCEPTIONS \\ OF THE OPTIONAL PRACTICAL TRAINING EXPERIENCE
}

James L. Monahan

Dr. Paul Watkins, Dissertation Supervisor

\begin{abstract}
The Optional Practical Training (OPT) program offers a pathway for international students to begin their professional career in the United States. Originally a one year training program, students with a degree in Science, Technology, Engineering or Mathematics (STEM) are now eligible for an additional two year OPT extension while on their student visa. The rapidly growing number of STEM students participating in an OPT experience indicates the increasing importance of this program to both students and employers. This qualitative study examined how students eligible for the STEM OPT extension perceive their transition from an academic setting to a work environment. Eight students on OPT were interviewed to identify the factors that had the greatest influences on their career decisions, and how OPT regulations and U.S. immigration policies influenced these decisions. These students acknowledged the professional opportunities that OPT provides, but also recognized that their OPT position was temporary and the program limits their career choices. They believe the ability for international students to secure employment in the U.S. is becoming more difficult due to the complicated nature of OPT regulations and uncertainties surrounding immigration policies. The students hoped universities could do more to inform employers about the OPT program in an effort to increase employer participation. They also acknowledged that their career success depends upon both outside influences and self-determination.
\end{abstract}




\section{Chapter One: Introduction}

The 2016 Open Doors data from the Institute of International Education (IIE, 2016) reported that for the first time over one million international (i.e., non-citizens with temporary residency status) students were enrolled in higher education institutions in the United States during the 2015-16 academic year (para. 1). Of these student, $36.8 \%$, 383,935 of them were enrolled in graduate level programs, more than double the number represented twenty-five years ago (IIE 2016, Academic Level dataset). Over the previous five years, international student growth at masters and $\mathrm{Ph} . \mathrm{D}$. level had grown by $6.2 \%$, outpacing domestic student growth, which only grew by $1.1 \%$ during the same period (Okahana, Feaster, and Allum, 2016, p.57).

The Council of Graduate Schools reported that $18.9 \%$ of the $1,782,364$ graduate students at U.S. institutions were temporary residents (Okahana et. Al., 2016, p.38), and that international students make up more half of the total enrollment in the broad fields of 'Engineering' and 'Mathematics and Computer Sciences' (p.38). The National Science Foundation (NSF) reports that international students account for over half of the students enrolled in specific graduate level programs, including $64 \%$ of graduate students in Computer Science, $60 \%$ in Statistics, and 56\% in Engineering (NSF Survey of Graduate Students, 2016, citizenship data set). Electrical (72\%), Petroleum (72\%), Industrial (55\%), Chemical (54\%), Mechanical (54\%), Materials (53\%), and Civil (51\%) engineering indicated that over half of their student were international, and each of these programs currently admit more than $50 \%$ of their full-time graduate students from outside of the U.S. (NSF, 2016, citizenship data set). These statistics demonstrate the importance of international students to many graduate school programs, both in terms of the tuition 
dollars they generate and the intellectual capital that they bring to the U.S. universities. These number also indicate that international students are likely to be a key source of talent for U.S. employers in the years to come, especially in high technology sectors of the economy.

In 2012 the Council of Graduate Schools (CGS) commissioned a study entitled "Pathways through Graduate School and into Careers" to collect data on the views of students, universities and employers regarding how graduate students obtain information about their chosen career field and how well-prepared these students are to enter that field upon graduation. The report found that faculty members were the primary source of career-related information for graduate students (CGS, 2012, p. 19), and that university administrators, particularly graduate school deans, worried that this could be problematic. These administrators noted that faculty members "understandably tend to be most aware of their own career trajectories" (p. 22) in teaching and research, rather than the broader range of career options available outside of academia. Meanwhile, employers participating in the study indicated that "graduate degree holders bring value to their organizations ... [because] these employees have the advanced knowledge that allows them to quickly engage in their work. However ... [some] lack certain other skills necessary for success on the job, such as skills related to working in a team environment, creating and delivering presentations, and project management” (p.1).

The Pathways report made several recommendations to improve the connections between graduate schools and employers, and outlined ways that these two stakeholders could further assist graduate students as they launch their careers. The recommendations included increasing the number of internships and other work-related training 
opportunities available to graduate students in a nonacademic environment (CGS, 2012, p.33). The report's authors argued that these types of experiences have the potential to strengthen the skills that students need to succeed in a work environment.

Students are not the only ones to benefit from such programs, however, employers also see benefits. The Pathways report pointed out that internships and work related training opportunities “broaden the students' views and understanding of the careers for which their program of study qualifies them ... [and they offer] employers a chance to evaluate a potential employee" (CGS, 2012, p. 34). In other words, the employers get to see if a recent graduate is a good fit for their company before committing to hire them long term.

While the Pathways report did not directly address international students, U.S. immigration policy does allow international students to participate in such work related training programs. The U.S. Citizenship and Immigration Services (USCIS), a division of the Department of Homeland Security, identifies two such programs that are authorized by the U.S. government: Curricular Practical Training and Optional Practical Training (USCIS I-9 central, 2015, para. 5\&6). Curricular Practical Training (CPT) is training that is specifically required as part the curriculum of a degree program, and it is completed before the student graduates. Optional Practical Training (OPT) is a program that allows international students to receive workplace training in a temporary position immediately after graduation. The "training must provide valuable work experience by sharpening and adding to the skills [the student] is learning in school" (USCIS Practical Training, 2017, para. 1) and therefore, the position must relate directly to the student's academic major or course of study. 
Due to immigration regulations, international students are often restricted from working off campus while they are studying. Therefore, these programs are particularly important to them as they seek to gain the experience necessary to launch a successful career. Because CPT and OPT are considered to be a part of the educational experience, students can remain on their student visa, and they are allowed to stay in the U.S. during this experience without having to secure a work visa (USCIS Visa Guide, 2017, para. 3). The university remains responsible for immigration related support services for these students, which is an important incentive for employers. If employers were required to sponsor these students for work visas, they might be unwilling to offer post graduate training opportunities to international students because of the added bureaucracy and expense required by work-related immigration regulations.

In 2016, the Institute for International Education reported that the number of international students participating in OPT in the United States grew by $22.6 \%$ over the previous academic year (IIE, 2016, para. 1). During the 2015/16 academic year 147,498 students were on OPT, representing $14 \%$ of the international student population in the United States (IIE, 2016, Academic Level datasheet). With such large and growing numbers, the need to examine the impact of the OPT program has become particularly important, so that key stakeholders in education can better understand how it impacts participating students as they transition from academia into the initial stages of their career.

\section{Purpose of the Study}

International students are likely to face unique challenges during their transition into a work environment. When searching for an employment position, they generally do 
not have an extensive network of family, friends, and colleagues in the United States that can serve as a source for job leads. If English is not their native language, they must overcome language and communication issues during the job search and interview process. The language barrier may include difficulties expressing themselves fully in interviews or written communications, such as cover letters and resumes. In addition, without previous work experience in the United States, international students may be unfamiliar with U.S. customs and workplace etiquette even after graduation. An OPT experience may be the first time these students are confronted with such challenges outside of the academic environment.

Like their domestic counterparts, international students are likely to seek guidance from their academic advisor or a trusted faculty member. Other sources of assistance may include the university's career center or international office, which can help them with the processes needed to secure an OPT position and transition into their career. The Council of Graduate School's 'Pathways' report identified significant concerns about the services universities provided to all graduate students in the area of career guidance (CGS, 2012, p.22). These concerns, along with the additional challenges faced by international students, suggest that more information is needed about how international students perceive the assistance that they receive from their university. This study hopes to add to the knowledge available regarding the transitional experience that these students undergo when participating in an OPT program and to explore the perceptions of international students as they begin their careers.

The study will ask these students to look back at their academic experience and how it has impacted their career path and decision making process. The study will utilize 
qualitative methods in an attempt to identify resources utilized by international students who have already completed a graduate level degree program in a STEM related field and who are currently participating in an OPT experience. In particular, it will examine which resources assisted these students in their transition from university studies to work. Furthermore, the study will explore the students' perceptions of their career path and how, as an international student, this path may be impacted by immigration policies in the United States.

Three broad research questions will guide this study. They focus on the students' perceptions of their transition into the workforce, while attempting to overlay an important policy discussion currently taking place in the United States onto the data collected. The research questions are:

1. How do recently graduated, international students with a Master's level degree in a STEM field perceive their transition from academic study to work in the United States?

2. What factors do these students identify as having the greatest influence on their career path decision-making process?

3. How do the immigration policies, which allow employment training after graduation, impact early career path decisions for international students in the United States?

The study is intended to be useful to universities as they seek to improve career related services to their international graduate student population. In addition, the study may provide valuable information to those interested in the current debate surrounding immigration policies in United States. 


\section{Description of the Theoretical Framework}

The proposed study will utilize qualitative methods to gather data on international student perspectives. The research will be conducted in the constructivist paradigm where the researcher and the participants will attempt to reach an understanding of the perspectives of a selected group of participants. In particular, the theoretical framework of social capital and how it relates to access to community resources and workplace opportunities will orient the study.

Social capital refers to the concept that social relations have productive benefits. It is most often used as a theory in sociology, where it has been described it as "a resource that actors derive from specific social structures and then use to pursue their interests; it is created by changes in the relationship among actors" (Baker 1990, p. 5). This concept is often loosely defined, and frequently dependent on the context in which it is used, but it has become an important lens through which to view societal influences on individual success. The idea can be used to explain how an individual is helped by their connections to a society, or hurt by their lack of connections.

International students leave their home countries and are forced to find new social structures and relationships upon arrival in the U.S. They are plunged into a new culture with different priorities and socially constructed realities, and they must learn to navigate these realities to succeed. Students must develop social relationships with their professors, classmates, and others at their university in order to complete their degree. This process can manifest itself differently for different students, and can result in differing degrees of success. For example, some international students may be willing to go to a professor's office hours for assistance with an assignment, and because of this 
interaction, be comfortable asking for a letter of reference at a later date. While another student who does not feel comfortable approaching a professor for assistance because of cultural norms in his country, and chooses instead to double his efforts in the library in an attempt to understand the problem, loses the ability to obtain a personalized reference letter at a later date. The first student gained social capital, while the second did not. How this social capital is transferred into a workplace training environment during the OPT experience is the broad lens through which this study will examine the perceptions of these students.

\section{Rationale for Using Qualitative Research Methods}

Any study involving international students must acknowledge the fact that for many of the participants English is not the individual's native language. Students at U.S. institutions are required to reach a certain proficiency level in English to enroll in academic coursework, but proficiency in any language is based on several levels, namely reading, writing, listening, and speaking. While most international students achieve proficiency in most of these levels over time, few claim to be highly proficient in all. Therefore, while an individual might have the ability to understand a particular question fully, he/she may not be able to answer the question succinctly because his/her spoken vocabulary lacks the necessary terms to provide a quick answer. Or a student may have excellent reading comprehension and be able to correctly answer multiple choice questions easily, but will struggle to write a cohesive answer to an essay question.

The language barrier can be problematic for any researcher attempting to collect data from individuals who may not be fluent in the language of the study. However, by utilizing an open-ended interview process, the researcher is better able to seek 
clarification and to ask follow up questions to flush out a full answer from the interviewee. By choosing a qualitative approach, misinterpretations can be minimized. Such misunderstandings could spoil the data collected in a quantitative study that relies on multiple choice questions or written essays.

Furthermore, the international student experience can vary dramatically depending upon many factors, including country of origin, religion, customs, and language. By using qualitative methods that allow these students to speak without categorizing their answers (as a multiple-choice survey might), a student's opinions and interpretations may emerge during the interview that were unanticipated, but provide insight. The researcher believes that quantitative methods are less likely to capture the subtleties of the international student experience in transitioning from academia to employment, which is the intention of the study.

Finally, many individuals who come to study in the U.S. also hope to begin their career in the United States. These students are often aware, at least to some extent, that immigration regulations may require them to return to their home countries, and/or limit their ability to find work in the United States. This reality can cause the individual to be suspicious of any request for information about their future intentions regarding immigration. While a qualitative study may not be able to remove these fears, a quantitative survey would allow these individuals to mark answers that they believe to be the 'correct' response rather than reflect their true opinion. Students who want to protect their immigration status could be fearful that a 'wrong' answer could get them deported. For this reason, they may be tempted to provide answers that they believe an immigration officer or a Designated School Official at the university wants to hear, rather than their 
actual opinion. While a qualitative study cannot entirely eliminate this possibility, the researcher hopes that by interviewing individuals who have already received their degree and obtained a job, even if it is temporary, may be more willing to share honest reflections regarding the assistance that they received in their transition to work.

\section{Definition of Terms}

International Student: For the purposes of this study, the researcher will use the definition of international student provided by the Institute of International Education and utilized in their Open Doors report. In this report, "an international student is defined as anyone studying at an institution of higher education in the United States on a temporary visa that allows for academic coursework. These include primarily holders of $\mathrm{F}$ (student) visas and $\mathbf{J}$ (exchange visitor) visas. ... Individuals who have permanent residency or a separate work visa are not counted ... [but] those who were enrolled at U.S. colleges and universities and stay on after their studies for Optional Practical Training [are included]" (IIE, 2016, FAQs para. 4\&5).

Optional Practical Training (OPT): OPT is defined by U.S. Citizenship and Immigration Services (USCIS) as "temporary employment that is directly related to an F1 student's major area of study" (USCIS Students and Exchange Visitors, 2016, para. 1). F-1 refers to the most common visa issued to international students studying in the U.S. A student must be working towards a degree at a U.S. institution to be eligible for an F-1 visa to remain in the country legally. Students must apply to participate in an OPT by "requesting the Designated School Official (DSO) at your academic institution to recommend the OPT" (para. 4) to the USCIS. If USCIS approves the request, the student may participate in job training legally in the United States for up to twelve months, and 
students with a degree in a STEM field may qualify for an additional 24-month extension of their OPT if their employer has registered with USCIS (para. 3).

STEM degrees: The acronym S.T.E.M. refers to Science, Technology, Engineering and Mathematics. USCIS has established a list of STEM degrees that include bachelors, masters, or Ph.D. degrees from an accredited university in the following courses of study: Computer Science Applications, Actuarial Science, Engineering, Engineering Technologies, Science Technologies, Biological and Biomedical Sciences, Mathematics and Statistics, Military Technologies, Physical Sciences, and Medical Scientist (USCIS Practical Training, 2016, para. 4).

F-1, J-1, and H1-B Temporary Visas: The U.S. government issues a wide variety of visas to non-citizens allowing them to remain in the country legally for a specific purpose. These visa types are defined by U.S. laws passed by Congress and known as the Code of Federal Regulations, commonly referenced as 'CFR'. These are published electronically by the U.S. Publishing Office on their website (USCIS Laws, 2016, para. 1). F-1 and J-1 visas are both types of visas issued to individuals who have been approved to study at an accredited educational institution (U.S. Visas, 2015, para. 2), and the rules governing these visas can be found in CFR title 8 part 214. The visas allow these individuals to remain in the country only as long as they are enrolled in coursework or training affiliated with the institution that has admitted the individual as a student. The individual must provide the school with information regarding their residence during their time in the U.S. and the school reports this information to the U.S. Department of Homeland Security. There are several differences between an F-1 and J-1 student visa, but the primary differentiation is that the J-1 visa has a two-year home rule. This requires 
J-1 students to return to their home country for a period of two years before they can apply to return to the United States for work or other non-tourist related purposes (U.S. Visas, 2015, para. 2). An H1-B visa is a temporary work visa that allows a non-U.S. citizen with a higher education degree the right to work legally in the country for a temporary period of time. The employer must file a petition with USCIS on behalf of the worker, pay processing fees, and verify that the job is a specialty occupation that requires a degree (U.S. Visas, 2015, para. 2). The H1-B visa is particularly controversial issue in U.S. politics at this time, but the research proposed here does not apply to the H1-B program. It is important to recognize this visa type, however, since it is a common next step for international students who wish to remain employed in the U.S. after completing their studies.

\section{Significance of the Study}

As the population of international students studying in the United States increased over the past century, attention to the adjustment issues that these students face as they transition into the U.S. education system grew dramatically. Organizations such as NAFSA and the Institute of International Education hold frequent conferences, workshops, and webinars designed to assist practitioners in the field so that they may better serve these students. These organizations publish magazines, studies, and reports aimed at faculty members and educational administrators to provide them with insights and techniques to improve the services provided to international students. Scholarly journals, including The Journal of Research in International Education, regularly feature studies relating to international student retention and persistence to graduation. 
Less attention has been paid to the path these students take when moving from the academic setting into their careers. Perhaps this is because international students are expected to return to their home country upon graduation, or it may be because universities have few obligations to provide networking opportunities or other services for their alumni living abroad. However, competition between educational institutions to attract students has led universities to pay more attention to the value of their diploma in the marketplace, and this has begun to shift more focus onto how well universities are ensuring successful career outcomes for all students.

Examples of this shift include the publication of "return on investment" rankings by organizations such as Payscale.com. These rankings look at the salaries graduates make both upon graduation and at the mid-point in their careers, as compared to the cost for a student to attend a particular institution. Schools with strong programs in the STEM fields tend to do particularly well in these rankings, as jobs in these fields pay higher starting salaries than those in social science or humanity related fields. These rankings provide alternate data to the traditional college rankings by publishers such as U.S. News that have been criticized for relying on subjective metrics which value name recognition, impressions, and historical reputations over numerical assessments. Newsweek published its first "Best Investment" ranking in August 2012; in 2014 USA Today offered a ranking of "Colleges where graduates make the highest starting salaries"; and the Princeton Review published a ranking of "Colleges That Pay You Back" in February of 2015. With these types of rankings appearing more frequently in the press, universities have begun to better track successful career outcomes for their students and provide resources toward services that boost students' career potential. These statistics are 
frequently used in recruitment materials for the institution, and they help the university gain a foothold in these alternative types of rankings.

With the large percentage of international students enrolled in STEM graduate programs, U.S. institutions would be well served to learn about the factors that influence the career path of these students. For international students, the decision of where to begin their career, either in the U.S. or their home country, is an important one. Research has suggested that over $50 \%$ of international students are interested in remaining in the United States to start their careers (Musumba, Jin \& Mjelde, 2011, p. 503). Generally, this interest is "attributed to the favorable socio-economic conditions that exist in the United States" (p. 503) which translate into better career opportunities and higher salaries for these individuals. For STEM students, opportunities to work in a high tech field are often more readily available in the United States than in their home countries.

Immigration policies enacted by the U.S. Congress in 2004 placed new limits on the number of work related visas awarded each year to foreign citizens - capping the number of $\mathrm{H} 1 \mathrm{~B}$ visas at 85,000 (USCIS H-1B, 2016, section 4), and this has impacted the career paths available to international students wanting to remain in the United States. These limitations have also impacted U.S. employers, particularly those seeking employees with advanced degrees in the STEM fields. In an update to the OPT rule published by the Department of Homeland Security (DHS), the need to keep more of these students in the U.S. was highlighted because it benefited "the U.S. educational system, U.S. employers, and the broader U.S. economy... by helping to ensure that the nation's colleges and universities remain globally competitive... [and by] increased ability to rely on skilled U.S.-educated STEM OPT students" (Federal Registrar, 2016, p. 
13043). DHS went on to argue that the nation benefitted from the retention of these students "through increased research, innovation, and other forms of productivity that enhance the nation's economic, scientific, and technological competitiveness" (p. 13043). This rule sided with employers who had argued that they need these students because they are unable to fill their most technically advanced positions with the limited number of domestic students choosing to obtain an advanced degree in a STEM related field. They also argued that they are losing qualified employees to other countries because recent international graduates were unable remain in the U.S. after their studies due to the H-1B limits.

To ease this shortage of highly trained professionals available to U.S. employers, the Department of Homeland Security authorized an extension to the OPT program for students who have earned a degree in a STEM program (NAFSA, 2016, para. 1). The OPT program had been traditionally limited to twelve months of full time employment, however, a 17-month STEM extension (to 29 months in total) was initiated in 2008 in response to the employer pleas for more international student graduates to fill their open positions. This extension was enthusiastically received by both employers and students, as is evidenced by the growing number of students who participate in this program. During the 2006/07 academic year only 41,660 students participated in OPT (IIE, 2016, enrollment trends data). Two years later, these numbers had increased by $60 \%$ to 66,601 , and ten years later in 2015-16, the number had grown to 147,498 (enrollment trends data).

The extension served to widen the pool of individuals with STEM degrees who were eligible to work in the U.S., even if this eligibility was only temporary. 
Furthermore, it gave employers an additional opportunity to secure an H1-B work visa for an individual that they wished to hire. Before the extension, if a company did not get an H1-B application submitted promptly, all the available visas would be awarded and there would not be a chance to hire the international student until the following year, after the student's visa expired. The 17-month extension for STEM degree holders on OPT allowed employers a second opportunity in the following year to request a temporary work visa for a non-U.S. citizen.

The extension was not without controversy. On March 28, 2014 a lawsuit was filed by the Washington Alliance of Technology Workers (WashTech) to end the entire OPT program (NAFSA, 2016, Focus on STEM OPT para. 3). WashTech's complaint stated that individuals who enter the U.S. on a student visa can remain only for the purpose of pursuing their course of study. The U.S. District Court for the District of Columbia, however, ruled that the OPT program had existed since 1992 without challenge, and therefore, the statute of limitations to challenge it had passed, but the extension, which was implemented in 2008 , could be challenged. The court decided that WashTech had standing "having identified members who asserted that they faced increased competition in the job market as a result of the 2008 STEM OPT rule" (para. 3). As a result of this lawsuit, in October 2015, the Department of Homeland Security proposed a new STEM OPT rule to replace the one challenged in court. This new rule replaced that 17 -month extension with a 24-month extension, and it put in place new requirements that employers have a mentoring and training plan in place for the student. These plans are intended to demonstrate that the OPT position is a continuation of the student's course of study. Employers must certify that "the student on a STEM OPT will 
not replace a full- or part-time, temporary or permanent U.S. worker, and the student's opportunity assists the student in reaching his or her training goals" (NAFSA, 2016 STEM OPT Rulemaking, Mentoring section para. 6).

These changes took effect on May 10, 2016, and while there continues to be debate surrounding the program, it remains popular, as evidenced by the strong growth in the number of OPT participants, including a 22\% increase in the past year (IIE, 2016, Academic Level data). The spike in participation likely indicates that international students view this policy as an opportunity which can assist them in their careers. Certainly many of them see OPT as a chance to gain important work related skills, and some hope that it "will serve as a gateway to longer-term U.S. employment" (Kato \& Sparber, 2013, p. 109). But research has shown that career decisions, including the decision to remain in the U.S., are complex, and multiple factors influence the decision making process (Musumba, Jin, \& Mjelde, 2011).

These factors include the strength of the student's family ties and the source of financial support for their education (Shen \& Herr, 2004), their capacity to overcome language and acculturation issues (Sangganjanavanich, Lenz, \& Cavazos, 2011; Reynolds \& Constantine, 2007), and their ability to establish key personal and professional relationships (Popadiuk \& Arthur, 2014). Musumba, Jin, and Mjelde's (2011) survey of 470 international students found that the primary motivation for where these students chose to start their career is "where they have more and better career opportunities, receive higher salaries, and have increased civil liberties" (p. 501). If this is the case, immigration policies that increase career opportunities, such as the extension of eligible 
OPT training, could to have a significant impact on the career decisions made by this segment of the student population.

As U.S. universities continue to recruit and rely on international students to meet enrollment goals for their graduate programs, it will be important for these institutions to understand the motivations that guide these students. The opportunity to participate in an OPT experience may be an important motivating factor, but little academic research can be found that isolates students on OPT for study. This study aims to improve our understanding how these students perceive their transition from academics to the workforce. In the process, it could help identify improvements to the services universities provide to their international students. The data collected could also provide insights relevant to the immigration policy debate underway in the U.S. at this time by helping policy makers understand the impact of recent changes to the OPT program. In order to accomplish these goals, however, it is necessary to first explore research that has already been done in these areas. 


\section{Chapter Two: Literature Review}

As international education has grown, so has the amount of research conducted on numerous topics relating to international student adjustment and retention issues. In addition to articles found in a wide variety of educational research publications, several peer-reviewed journals are dedicated solely to this field of study, including the Journal of Studies in International Education and the Journal of Research in International

Education. Although the research has significantly advanced understanding on numerous aspects of international education, very little research has been done on how these students transition to work. With the recent growth of Optional Practical Training opportunities for international students, it is somewhat surprising that no peer reviewed articles related to OPT could be found in a recent ERIC database search. This study will help to fill the gap in research relating to OPT by gathering data relating to student perceptions of the program and how it fits into the early career related decision process of international students. The growing importance of international education provides a rich foundation of information from which to begin this study.

\section{Common Issues Faced by International Students}

A large amount of published research has focused on the issues faced by international students who come to the United States to complete an academic program (Andrade, 2006; Stoynoff, 1997; Trice \& Yoo, 2007; Poyrazli \& Kavanaugh, 2006). This focus is not surprising, considering university officials who recruit these students must ensure that they can successfully transition into the American education system and remain through to graduation. The stress of transitioning into a new culture and academic system has been thoroughly studied and shown to have significant implications 
for international student success. Harvey Charles and Mac Stewart (1991) pointed out eight specific issues that academic advisors must understand in order to assist international students, and these themes can be found throughout the literature regarding international students. The broad categories of issues as identified by Charles and Stewart are:

1. Cultural Sensitivity

2. Language Limitations

3. Adjustment Issues

4. Academic Overload

5. Academic Restrictions

6. International Students' Perceptions of Advisors and Other Authority Figures

7. Differences in Educational Systems, and

8. Dealing with Ambiguity (p.174.).

Many of these issues appear frequently in research relating to international students, and they can apply not only to education adjustment issues, but also to the issues faced by these students as they transition to employment (Crocett \& Hayes, 2011; Arthur \& Popakiuk, 2010), For this reason, it is worthwhile to briefly define each of them.

Cultural Sensitivity is the concept that "International students may demonstrate cultural differences in terms of their concept of time, their use of space, or their value orientations" (Charles \& Stewart 1991, p. 174). For example, different cultures prioritize attributes such as punctuality and personal space differently than Americans, so an international student may inadvertently offend by arriving late or invading the personal space of his/her colleague. While these challenges may seem relatively minor, studies 
(Andrade, 2006; Poyrazli \& Kavanaugh, 2006) have shown that these culturally sensitive issues can create stress and anxiety.

Difficulties with the English language can also affect both academic and social adjustment for international students (Andrade, 2006; Trice, 2003). Learning a new language can be extremely complex, as full understanding goes far beyond grammar and vocabulary. Understanding humor, sarcasm, and idioms require years of immersion into a culture and language, and therefore, many students who are still English language learners feel that they are at a disadvantage when attempting to understand lectures, build relationships, or interview for an internship or other professional appointment.

Adjustment issues, such as obtaining housing, finding a place to worship, struggling with finances, or dealing with homesickness, can impact all students, both domestic and international. But often these issues are magnified for international students, as their support network is further removed and less able to assist them in a different country (Reynolds \& Constantine, 2007; Popadiuk \& Arthur, 2014). For example, a new international student may have little concept of laws prohibiting housing discrimination, leaving them more open to being taken advantage of by an unscrupulous landlord. A student raised in the Hindu tradition may be unable to find a temple to allow him to practice certain religious traditions that he has taken part in throughout his life, and the student who has never had to shop for food and manage expenses may find these tasks overwhelming in a new culture at first. Universities and many affiliated organizations offer services to assist international students with such adjustment issues, but they cannot be ignored as a source of stress and a reason that students may fail to graduate. Similarly, while most students find ways to deal with these issues while they 
are students, when they transition into an OPT position or find employment in the host country, these adjustment issues can begin again, as the student must start over in a new city with new challenges to overcome.

Academic Overload and Academic Restrictions are two issues that specifically refer to the educational experience, but can have implications for student careers. Academic Overload refers to the issue of an international student taking too many courses in an effort to finish a degree quickly due to time or financial constraints, and can be a particular problem for students with low English language skills. Academic Restrictions refer to the limitations that students may face regarding the courses that they are allowed to take or field of study that they are allowed to pursue which are placed on them by their financial sponsors, parents or even government. Students may not be able to change majors or take classes unrelated to their primary field of study, even if they wish to act otherwise or have talents that are better suited to a profession unrelated to their degree. Frequently, "these restrictions are tied to financial support, and not acting in compliance may result in cessation of funds" (Charles \& Stewart, 1991, p. 178). While neither academic overload nor academic restrictions are directly related to the issues that the individual may face when transitioning to work, it is important to recognize the pressures that these kinds of issues can put on an individual facing career decisions.

The relation that international students have with authority figures is often tied to their cultural background. The ability to build social capital is connected to a student's ability to interact in an appropriate way with individuals in positions of authority. For example, in many East Asian countries, a very formalized relationship exists between students and teachers, or employees and employers. It can be considered disrespectful to 
look an authority figure in the eye, whereas in the U.S. this is expected. And whereas students and workers are expected to assume individual responsibility in the U.S., in other countries, authority figures are expected to tell those underneath them exactly the actions they expect. There are numerous other types of perceptions of authority that can cause the international student or new employee to behave incorrectly when viewed from a western perspective. Charles and Stewart (1991) discussed this issue in relation to student advising, but similar issues arise in both classroom and workplace settings.

Differences in the educational system can also cause problems for students - from not having the required prerequisite skills to succeed in a course, to not understanding the informal nature of the American classroom. International students are sometimes graded lower than their domestic counterparts for failure to participate. Yet these individuals come from a system where rote memorization and careful attention to a lecture are judged important to academic success, and interaction in the classroom is discouraged. International students must learn to function appropriately in the American education system, and similarly they will need to learn to function in an employment system with rules that they may not fully understand. In other words, students must learn how to build their social capital to be successful. Understanding workplace etiquette, for example, is a common concern for international students entering the workforce in a foreign country (Crockett \& Hayes, 2011, p. 69), and these types of differences can cause stress similar to that which the individual faced when entering a new educational system.

The final issue identified by Charles and Stewart is what they have called dealing with ambiguity. This generally refers to the challenge faced in cross-cultural communication of any sort. It is sometimes difficult for the international student to know 
when to ask for additional information, and it is difficult for the American to know when they need to provide more details or are over-simplifying so much that it is insulting.

There will always be some ambiguity in encounters and relationships between international students and those with whom they interact, and it is important recognize the challenge that this presents, even if a solution is not possible. Ensuring that individuals trained in cross-cultural communication techniques are present in advising offices and other key positions at a university can be important when serving international students.

\section{Advising and Mentoring}

The need to mentor and advise students has long been recognized in higher education, but current practices can be traced to influences that began to appear in the 1970s (Habley, 2000, p. 35). Faced with the potential for declining enrollments as the baby boomer generation passed through their traditional college years, colleges "were forced to look seriously at ways in which they could better serve, satisfy, and retain the students who enrolled" (p. 35). Beginning in 1975, studies by Vincent Tinto and others began to show that involved students are more successful and likely to remain in school than those who are not, and if formal advising policies encouraged ongoing interaction with the student, this practice would result in more involved and successful students (Frost, 2000). Formal advising practices were, therefore, viewed as an important tool in reaching student retention goals.

Research demonstrated that "retention was consistently found to be dependent on a combination of academic and personal needs, calling for collaborative efforts to enhance students' integration into the learning community" (McGillin, 2000, p. 368). In 
fact, some researchers have suggested that graduate advising not only promotes a student's ability to function in the educational environment, but is also one way in which "students are socialized into their respective professions" (Schlosser et al., 2011, p. 6). Several recent studies, (Rice et al., 2009, Trice and Yoo 2007, Schlosser et. al 2011) have shown that quality advising can have a positive impact on international student adjustment and success.

The advisor-advisee relationship is designed to help students navigate the academic requirements of a degree, and it also has the potential to promote a student's professional and career development (Schlosser et al., 2010). Research has suggested that "the quality of the advising relationship is a key predictor of adjustment and success of graduate students" (Rice et al., 2009, p. 376). While several studies examining international graduate student perceptions of their international experience have indicated that a majority of international students are satisfied with the advising they receive (Trice \& Yoo 2007, Rice et al. 2009, Knox et al. 2013), studies also point to significant challenges to quality advising of international students. These challenges include discrepancies in communication (Kim, 2007), culturally insensitive mentoring (ParkSaltzman, Wada and Mogami, 2012), and a lack of international focus in the curriculum (Trice \& Yoo, 2007). Rice et al. (2009) found that one in four students indicated that they would change advisors if they could, and $17 \%$ expressed an overall dissatisfaction with their advising, citing the poor interpersonal quality of the advising relationship and a desire for their advisor to better understand their cultural values, special needs, and language difficulties. 
Scholars have noted that the advisor-advisee relationship can have a significant positive influence on the graduate student. Benita Barnes, Elizabeth Williams and Martha Strassen (2012) summarized some of the research that has been conducted regarding why this relationship is so important. They state that advisors "help their advisees develop the habits of mind conducive to scholarly work ... are an important source of support ... provide advisees opportunities for professional development ... [and play a] role in the socialization and satisfaction of their advisees" (p. 311). Of course this is only the case if the relationship is a positive one. As Lewis Schlosser et al. (2011) point out, "advising refers to a relationship that may be positive, neutral, or negative with regard to valence, and the content of said relationship will also vary based on the degree to which the advisor facilitates the advisee's professional development" (p.7).

Graduate level education is inherently based on professional development. Students focus their studies in one key area, without outside curriculum requirements in other subject areas, in preparation for employment in a particular field of work. The end result of a Master's or PhD level program is to provide an entry into a particular profession, and therefore, the graduate advisor relationship is likely to be judged on the ability of the advisor to assist the student into the professional arena.

Mentorships, on the other hand, are inherently positive, and this is a key distinction between mentoring and advising. "As advising relationships become more globally positive, they begin to share characteristics with mentoring relationships. Hence, improving the overall quality of advising relationships stands to enhance the frequency of mentorships, which will in turn, benefit both students and faculty" (Schlosser et. al., 2011, p. 5). Advising can be a gateway to mentoring, but the act of 
advising itself is a more formalized approach to assisting a student. For most graduate students, this takes place within the academic department in which they are enrolled. Graduate students always have an advisor, but they may or may not report having a mentor. Researchers such as Lewis Schlosser, who has devoted much time to studying graduate advising relationships, suggest that graduate-level advising "has the potential to profoundly affect a student's professional development and career path" (p. 4) particularly when the advising relationship looks like a mentorship.

International students "view their advisors as potential sources of information and support ... but they may have different expectations about their relationships with advisors compared to domestic students" (Curtin, Stewart \& Ostrove, 2013, p. 113). Several studies (Curtin, Stewart \& Ostrove, 2013, Andrade, 2008) found that international students, more than domestic students, looked to their advisors for a relationship based on personality and interpersonal closeness, perhaps as a mechanism for relieving acculturation stress. While international students did not self-report a concern with social integration, only academic success, "advisor support was related to both higher levels of sense of belonging in one's department, as well as positive academic self-concept" (Curtin, Stewart \& Ostrove, 2013, p. 130). These findings seem to indicate that advising can be particularly important for international students as they work to integrate into an academic setting.

\section{Career Decisions}

After earning a degree from an institution of higher education in the United States, international students are faced with a number of career decisions. The most important of these is probably to return to their home country immediately or attempt to 
gain some practical experience in their field in the United States, or possibly another country. This practical experience can be a stepping stone to seeking longer term employment in the U.S. or simply a way to improve professional skills before returning home. In many cases, this decision is made for the student by whomever may have financed their education (Singaravelu, White, \& Bringaze, 2005). Those students who are sponsored financially by a company or government are often required to return for employment in their home country immediately upon graduation. These students may be attending school on a $\mathbf{J}$ visa which requires them to return home for two years before they have the possibility of applying for any type of work visa in the U.S., and although these students may have the opportunity to participate in OPT, permission may be contingent upon the financial sponsor's approval.

For those students with a choice of returning home or remaining in the United States, the decision is often one based on a wide variety of factors. Studies have indicated that "differences in the economic and political conditions [of a student's home country] explained the variation in foreign students' non-return rates. Students tend to return to rich countries and those countries close to the United states, although propensity to remain in the United States varies across countries" (Musumba, Jin \& Mjelde, 2009, p. 503). Although there are no comprehensive studies regarding preferences to return home, Musumba, Jin, and Mjelde (2009) found in a representative sample that $51 \%$ of international students indicated a preference to begin their career in the United states, while $22 \%$ preferred to start their career in their home country and $27 \%$ were not sure. In this study, respondents indicated a preference to remain in the U.S. because of "higher political stability and public safety, better gender equality, better access to recreational 
facilities, cleaner air and water, better appreciation for cultural diversity, a higher standard of living, and more educational opportunities for their children. On the other hand, respondents tended to indicate that they had better access to health facilities, better networking with fellow country persons, and less racial discrimination in their home country." (Musumba et al., 2009, p. 505). The most statistically significant of these factors for choosing to start a career in the U.S. were "better public safety, more private and public career opportunities, cleaner water, and a better standard of living" (p. 508).

This important study looked at the factors that influenced career location decisions involved 493 students answering 28 questions about their demographics and preferences. The researchers were able to examine a number of variables influencing the decision making process of these international graduate students regarding their career choices. Among their findings are the following:

Students in engineering, business, and science fields have a higher likelihood of preferring to start their careers in the United States ... [which] may be attributed to the level of technological and scientific advancements in the United States relative to the students' home countries. ... Females have a 15 percentage points higher probability of preferring to start their careers in the United States than males.... The longer students stay in the United States, the more likely they are to prefer to start their careers in the United States. ... [And] Married students have an increase of 16 percentage points over single students in the probability of preferring the United States (Musumba et al., 2009, p. 513-14). 
Those students who have difficulty integrating into the culture of the U.S., however, are 8 percentage points more likely to wish to begin their career in their home country.

The authors make two interesting speculations regarding the role that higher educational institutions play in the career decisions of international students. They state that "Universities with good social networks that help assimilate foreign students into the American lifestyle may be affecting student preferences as to where they prefer to start their careers" (Musumba et al., 2009, p. 514). They further suggest that the policies that American universities have adopted may be contributing to the brain drain from some developing nations. They argue that "Admission of students to technology and scienceoriented programs, providing funding to international students and allowing students many years to complete their studies contribute to students preferring to start their careers in the United States" (p. 515). This argument blurs the lines between the intentions of the university and the possible results of institutional policies, and it does not take into account the role of other players, such as employers seeking highly skilled labor, but it does raise interesting considerations for policy makers.

Nancy Arthur and Sarah Flynn (2011) conducted a qualitative study that yielded similar results regarding the factors that influence international students' decisions to return home or remain in the host country after graduation. They identified four core themes, namely "enhanced quality of life, career-related opportunities, enhanced work environment, and safety and political stability" (p. 227). Interestingly, they found that career decisions, similar to the decision to study abroad, were greatly influenced by family. Those students who indicated positive support from their parents to study abroad were also often supported in their decision to seek employment in the host country. 
Arthur and Flynn (2011) heard from those who participated in their study that many of the difficulties these individuals faced as an international student, such as cultural differences, the lack of a support network, and language skills, were also barriers to seeking employment. The students feared "not being culturally appropriate during job interviews, or being seen by employers as less desirable" (p.229). The study stressed that students expressed an interest in receiving very practical information regarding career searches, such as the logistics of applying for a job and how to network with employers. Another qualitative study that focused on international student's employment search in the United States also found that students felt that coping with acculturation issues was one of the most difficult issues. All of the participants in the study "agreed that lack of fluency in English inhibited their full self-expression in application materials as well as communications and interactions (both distant and face-to-face) with potential employers" (Sangganjanavanich, Lenz \& Cavazos, 2011, p. 22). They expressed a need for additional processing time during interactions because their vocabulary was limited, and that having an accent or speaking in broken English made them vulnerable to discrimination during the job search process. The other challenge frequently cited by these study participants was a lack of resources to help them understand employment rules and policies related to international workers. On the positive side, however, these individuals indicated that their multilingual ability was helpful in securing employment, and they recognized that they offered some unique skills, such as cross-cultural understanding and the ability to comprehend global trends.

Yih-Jiun Shen and Edwin Herr (2004) conducted a qualitative study of international students' career placement concerns that found these students used contacts 
in their academic departments far more than formalized campus career services. In addition, international students often did not receive formal assistance with basic job search skills, such as resume writing assistance and interview techniques. While these findings are interesting and suggest important implications for higher education practitioners, the study was conducted on students who were still enrolled in their academic programs and had not yet conducted a job search. It is unclear if students seek additional assistance once faced with this task.

Additional research in this area, such as a study conducted by Popadiuk and Arther (2014) on how key relationships factor into university-to-work transitions, and Sanganjanavich, Lenz, and Cavazos's (2011) study on the use of support groups to assist international students during the employment exploration and application process, also used students who had not yet graduated as subjects for their study. Other research has explored how specific difficulties, such as cultural adjustment problems, impacted the aspirations and career outcomes of international students (Reynolds \& Constantine, 2007). But the amount of research available relating to international students who have completed their academic coursework and successfully began to transition into the workforce remains small.

\section{Career Counseling}

International students frequently view the OPT opportunity as essential to their education "because they perceive that it provides exposure to the U.S. occupational system and allows an opportunity to develop specialized technical skills before returning home" (Crockett \& Hays, 2011, p.68). This can be particularly true of students who graduate in the STEM fields, as they may not have access to the same standards of 
equipment and technical facilities in their home countries. Perhaps because of this opportunity, recent studies have suggested that over three-quarters of international students reported an interest in both learning about occupational opportunities in the U.S. and in speaking to a career counselor regarding career plans and goals (Spencer-Rogers, 2000). But some studies have suggested that "international students are frequently unaware of supportive counseling services available through their university" (Sangganjanavanich et al., 2011, p. 18) or that these services are underutilized because of cultural disparities (Crocket \& Hays, 2011).

Research has suggested that services related to career needs for college students are primarily designed for domestic students (Crocket \& Hayes, 2011). But recent trends found in counseling centers at colleges and universities have begun to present ideas for culturally sensitive counseling services, including group counseling sessions, job search clubs, and marketing in multiple languages (Arthur \& Popadiuk, 2010, Bikos \& Furry, 1999, Gibson, 2005). Yet the services provided by American style counseling centers, including assistance with resume writing, interviewing skills, and job search assistance, remains a high priority for both domestic and international students alike.

International students also need assistance in understanding U.S. corporate culture, such as appropriate dress, punctuality, speech norms and eye contact during communication (Bikos \& Furry, 1999). Yang et. al. (2002) point out the difficulties that arise due to language barriers, particularly in the development of an effective resume and cover letter, including the differences between an American style resume and a curriculum vitae, which is more common internationally. Additionally, they point out that a strong accent or inability to provide quick responses to interview questions in 
English can be problematic for international job seekers. And Gibson (2005) points out that the entire job search process is often shadowed by questions of immigration and visa requirements that are rarely understood by most career counselors.

Cultural identity also plays an extremely important role in career counseling, as noted by Arthur and Popadiuk (2010). They point out that career ambitions and decisions are often tied to the interpersonal connections of international students, particularly ties to family. Parents may determine acceptable and unacceptable career choices for their children, and the need to adhere to family wishes may be the most important factor in career related decisions. Career counselors must be aware of the importance of such factors and provide guidance that is sensitive to the cultural identity of the student, which can be very different from the approach advocated with domestic students who often have strong individualistic motivations.

\section{Social Capital Theory}

With such a wide variety of factors influencing international student's educational and career decisions, it is important to consider a framework for examining how these students adapt to a new culture. The notion that our social relationships are productive in nature is the basis of social capital theory. Because international students must face acculturation issues, the ability to build social relationships are a key challenge for these students. As a student transitions into the workplace, additional acculturation issues may arise, and once again the ability to build social relationships becomes important. The extent to which this issue arises is the theoretical backdrop for this study.

Upon arrival in the United States, international students learn how to interact with others in the new cultural context in which they have been placed. They must learn about 
social norms and expectations of behavior, how to access information, interact with others appropriately, and generally understand how the system works. Frequently, these students do not have family or other relatives to assist them, and so they must build a network that allows them effectively function in society different from the one in which they were raised. The construction of this network is essentially the building of Social Capital, as conceptualized by Pierre Bourdieu.

Bourdieu was a French sociologist who wrote about the three sources of capital: economic, cultural and social. He defined "social capital as access to institutional resources ... made up of social obligations or connections, and it is convertible, in certain conditions, into economic capital" (Dika \& Singh, 2002, p. 33). In other words, the people with whom a student interacts can provide information and/or the tools necessary to obtain a specific goods and services. A clear example of this might be the professor who connects the student to an employer willing to hire him or her. This is particularly valuable to a student who does not have family to explain to them the best way to approach an employer in the U.S. or prepare for a job interview. If a student is able to quickly develop a network of people to trust, they will have a better chance to access the resources available in society that will allow them to reach their goals.

Social Capital is frequently conceptualized as the ability of "relationships and networks [to] generate access to institutional resources" (Dika \& Singh, 2002, p. 41). Social Capital theory recognizes that social interactions have productive benefits for both individuals and communities, and Bourdieu ultimately saw social capital as a way for the dominant class to preserve its dominant position in society. Social Capital can only be transferred if there is a level of trust between the parties engaging in the social 
interaction. This trust is often established by the appropriate use of social norms, something that is commonly learned while growing up in a particular society and must be learned by someone outside of that society.

The theory implies that until an individual gains social capital, many resources that an institution, such as a university or corporation, may consider readily available are actually inaccessible to certain individuals. For example, international students from a country that would not normally have a career placement office on a university campus, may not understand how to access career placement services in the U.S. Therefore, a resource that the university intends to provide to all students remains inaccessible to international students who do not have sufficient social capital to understand how to utilize the service.

Rodney Clifton (1999) argues that "to aid student's scholarly development, administrators, professors, and students themselves must develop networks of interaction, based on trust, so that norms, obligations, and expectations for scholarly work are increased [and] information channels are expanded" (p.114). In other words, in order for academic institutions to fulfill their mission to students, they must help foster social capital. Attempts to provide students with opportunities to build social capital can include initiatives such as new student orientations and first year experiences. Identifying which of these activities are most helpful for international students, who may begin their academic career with a minimal social support network, is important so that scarce resources may be allocated appropriately to these efforts.

In the end, however, the literature still views social capital as a somewhat fuzzy concept that is best utilized as a way to describe rather than explain inequalities. As Dika 
and Singh (2013) point out, "Bourdieu views his social capital as an open concept designed to guide empirical work rather than a causal model" (p. 44). Dika and Singh's synthesis of the use of social capital in educational research found that "social capital indicators and indicators of educational attainment are positively linked, but theoretical and empirical support could be stronger" (p. 41). They go on to argue that "nearly all of these studies focus on the conceptualization of social capital as norms rather than access to institutional resources" (p.43), as Bourdieu had argued. This makes it difficult to distinguish the difference between the sources of social capital, namely relationships, from the benefits gained from social capital. Essentially, social capital is criticized for promoting circular reasoning - does an individual who stays in school gain benefits in society or did that individual already have benefits, which allowed him or her to stay in school? Because of this problem of circular reasoning, the social capital framework serves the researcher better as a 'method to describe' than a 'way to explain' a cause or effect. If viewed in this context, it can be a useful tool for qualitative research.

\section{Social Cognitive Career Theory}

While social capital provides a perspective through which to view the adjustments that international students must make to their new culture, it is also important to understand some of the theoretical underpinnings of studies that examine student transitions to work more broadly. Career development theories attempt to describe and understand the process through which people relate to work and their role in it.

Early work theories looked at ways to match personal traits, or an individual's particular skills, to various occupations, while later theories built off this idea to examine how personality types could match with specific work environments. John Holland 
developed six types of personalities (Realistic, Investigative, Artistic, Social, Enterprising, and Conventional), and speculated that individuals with traits that matched these types would thrive in particular occupations (Leung, 2008). For example, those with a Realistic personality type are best suited to work in construction or farming, while those with an Investigative personality type would perform best as a scientist or doctor. The key to a successful career, therefore, is for an individual to find a fit between one's type and work environment. While Holland's personality types are easily understood and have proven stable and reliable over time, the theory gives little guidance for working with students to develop skills for a career.

Donald Super's Development Self-Concept Theory attempts to demonstrate how individuals can choose a career based upon what they have learned about themselves over time (Leung, 2008). The theory discusses the various stages through which individuals gain an understanding of their vocation. Starting with a growth stage as a child, where an individual forms a general vocational goal, through an exploration stage in one's teens and early twenties, where preferences are narrowed, to an establishment stage where individuals find a secure niche in a chosen field. This theory has practical implications for career counselors, as it allows them to help a student clarify their self-concept and identification in a particular occupation. As an individual tries different aspects of work, they can gain greater self-knowledge and understanding of the career path which is best for them. Success or failure in the classroom can help identify preferences for the job market, and a counselor can help a student develop a realistic self-concept and direct them to additional learning opportunities. 
Social Cognitive theory takes this concept further by looking at how an individual rates their own abilities and their ability to reach an identified goal. Bandura labels this as "self-efficacy or confidence in one's ability to perform a given task or set of tasks [and this] helps to determine whether an individual will initiate, persevere, and succeed at particular endeavors" (Lent, Hackett \& Brown, 1999, p. 299). Past success provides motivation to believe in future effectiveness, whereas, a failure can cause an individual to abandon a similar task more quickly. Therefore, career development is seen through this theory is an extended period of adjustment to discover what an individual is willing to attempt and how long they will persevere to master a specific task. As an individual moves forward in the career development process, they set goals based upon their determination to reach a specific outcome.

The theory highlights a number of "interrelated processes that that are manifest at various developmental points ... [including the] acquisition of positive yet realistic selfefficacy and outcome expectations ... and negotiation of social supports and barriers that affect the development of self and occupational beliefs and the pursuit of preferred academic/career options" (Lent et al., 1999, p. 300). In other words, while social cognitive theory stresses the importance of an individual recognizing their own strengths and weaknesses, they must also recognize the outside influences that can have a significant impact on career choices and opportunities. The theory places a strong emphasis on an individual's ability to be aware of the many influences on their career, both internal and external, and to make decisions based upon this knowledge.

Matching skills, abilities and even personality traits to career choices, as Holland suggests, can be important to a successful school to work transition. Gaining a realistic 
self-concept, as suggested by Super's model, can also be helpful to students as they seek experiences to help them determine their career trajectory. But Bandura's model provides a richer context for understanding how international student must negotiate the many influences which shape their career choices. A social cognitive view acknowledges that career decisions can be based on factors other than personal interests. Self-efficacy recognizes that "an individual's preferred option be compromised in favor of one that is either more readily attainable or more acceptable to his or her support system" (Lent et al., 1999, p.304).

Social cognitive theory suggests, as viewed through Bandura's model, that a student's ability and willingness to work toward specific career goals will be affected by how they view the outside support that they receive or the barriers that they face. Career counselors and others, who understand the big picture and help a student navigate through this complex reality can best help a student achieve his or her goals. Social cognitive theory presents a strong framework for understanding how an international student approaches the school to work adjustment process.

\section{Discussion of Immigration Policies Impacting International Students}

For international students starting their career, immigration policies play a significant role in their decision making process. As mentioned previously, these students must make the decision to return to their home country immediately after graduation to seek employment or to remain in the United States for additional practical training in their field of study under the Optional Practical Training option provided by U.S. immigration law. For the purposes of this study, it is important to have an understanding of the law and its implications for these students. 
OPT is available to any F-1 student for the purpose of gaining practical training to complement their studies. This rule was established under Title 8 of the Federal Code of Regulations that governs issues relating to aliens and nationality (USCIS Laws, 2016, para. 1). This part of the federal law established the United States Citizenship and Immigration Services, also known by its acronym, USCIS. USCIS has final authority for allowing any foreign citizen to enter and remain in the country under the rules outlined in Title 8. Part 214 of the law, which provides specific regulations for individuals entering the country temporarily, as non-immigrants, including those coming for educational purposes. This part of the law defines three different types of visas that a student can obtain - F, J and M - and the rules that go along with each of these (U.S. Visas, 2016, para. 2). The F visa is the most common type of visa awarded to individuals seeking a degree from a college or university in the United States. It is specifically intended for those seeking a degree in an academic field and is generally valid for as long as the individual takes to complete his or her degree.

The other types of student visas are $\mathrm{J}$ and $\mathrm{M}$ visas. $\mathrm{M}$ visas are given to those enrolled in vocational training programs, such as cooking or mechanics (U.S Visas, 2016, "Nonimmigrant Visa Categories" chart). These visas are not generally utilized by university students, particularly for those enrolled in graduate studies, and are limited to three years in length. J visas are intended for exchange visitors, including students and scholars (U.S Visas, 2016, "Nonimmigrant Visa Categories" chart). They are granted for a variety of academic purposes, including short term programs, such as semester or yearlong study abroad program, and research projects. Generally, students attending a university for the purpose of completing a degree do not receive a $\mathbf{J}$ visa, however, if they 
are sponsored by an employer, government, or other organization in their home country, this type of visa may be provided because of specific regulations relating to these types of programs. Neither $\mathrm{J}$ or $\mathrm{M}$ visa holders are eligible for OPT, however, they may have the opportunity to participate in similar practical training under another program (USCIS Practical Training, 2016, para. 1).

The rules on these practical training options are outlined in CFR214.2(f)10. The OPT program outlined in this section states that students in the United States on an F-1 visa are allowed to participate in 12 months of practical training related to their field of study (USCIS Visa Guide, 2016, para. 2) . Any student wishing to participate in this program must apply to USCIS through the college or university that issued the paperwork allowing them to obtain a visa. The college or university must recommend their participation in the program, and if approved, the institution will continue to be responsible for specific reporting requirements, such as providing a current address for the student to the Department of Homeland Security. Because the individual remains on a student visa, the employer does not have to pay any of the fees associated with petitioning the government for an employment visa. The employer must provide an official offer letter before the student starts the training, and inform the school if the student's training is terminated for any reason. In addition, under the updated OPT rules, the employer must certify a mentoring and training plan for the student (NAFSA, 2016, STEM OPT Rulemaking “Mentoring” section)

Students are required to find the training position on their own, just as any graduate would look for employment. They are given 90 days from the date they submit their application for OPT to secure a position (USCIS Practical Training, 2016, para. 3). 
If they do not secure a position in this time, they must return home. The student does not have to complete the entire 12 months of OPT with one company, and a student may complete some training before graduation, for example during a summer that they are not taking classes. Or they may train with one organization for six months and another for six months, however, the total cannot exceed 12 months, at which point their current visa expires and they must either return home or secure another student or work visa.

Should the individual find an employer interested in hiring them, the employer must then apply to the USCIS for a work visa for this individual. The most common is the H1-B visa, which is a temporary work visa (U.S. Visas, 2016, "Nonimmigrant Visa Categories chart"). In order to secure this visa, the employer must demonstrate that they were unable to fill the position with someone who is a U.S. citizen or holds a permanent residency in the United States. In other words, H1-B visas are intended to fill holes in the U.S. labor market where the demand for workers exceeds the number of qualified job seekers. In recent years, these jobs have tended to center around the fast growing high tech industries. The number of American students earning an advanced degree in the STEM fields has not kept up with the demand, and therefore, employers are turning to individuals from abroad, who have completed a degree at an American university, to fill these positions through the H1-B visa program.

Although the H1-B program was always intended to be limited, before the events of September 11, 2001, employers were able to easily secure H1-B visas for the individuals that they hoped to hire. New limitations to this program, however, occurred during Congress's review of the immigration policies in 2004, and strict limits on the number of H1-B visas were enacted and enforced by the Department of Homeland 
Security (USCIS H-1B, 2016, section 4). The result of this action led to all of the available H1-B visas being approved during the first few days of the application process, which opens on April $1^{\text {st }}$. Therefore, an employer wishing to hire a qualified international applicant for a position in May (or later) would have to wait until the following year to apply for the H1-B visa. In addition, approved H1-B visas do not take effect until October $1^{\text {st }}$ of the year in which they are approved. Therefore, an employer wishing to hire student who graduates in May, could have to wait until the following April to apply for the H1-B visa, and if approved, the student could not start working legally until October, a total of 17 months later.

By the mid-2000s tech companies, in particular, were feeling the impact of the new restrictions or 'cap' on the number of H1-B visas issued and lobbied congress to make changes that would allow them to hire more foreign workers to fill positions in their companies that required specific skills, such as an advanced degree in a STEM field. This problem was referred to as the H1-B cap gap, and Bill Gates, the founder and CEO of Microsoft, famously went to Washington and appeared before the U.S. Congress to ask them to solve this problem. The solution came in the form of a 17-month extension to the OPT program for students who had earned a degree in a STEM field. While this did not increase the number of H1-B visas issued each year, it allowed companies and their potential international employee a second chance to apply for the required visa. As a result, students with a STEM degree were allowed to participate in the OPT program for up to 29 months after graduation. After a court challenge to the STEM extension, the Department of Homeland Security revised the OPT rules in 2016 to include new certifications that the OPT opportunity assists the student in reaching his or her training 
goals, and increased the length of the extension to 24 months (NAFSA, 2016, STEM OPT Rulemaking, para. 1). As a result, under current regulations, international students with a degree in a STEM field may participate in OPT for up to three years.

While the intention of this change in immigration policy was to assist U.S. corporations, the implications are clear for international students. There is a possibility to remain in the U.S. longer after graduation, and therefore, have a potentially greater opportunity to find an employer willing to help secure a work visa. For students hoping for a career outside of their home country, the OPT extension may encourage them to look more closely at studying in the United States.

Whether or not a student considers OPT this during their deliberations regarding where to apply for graduate school is unclear, and a review of the literature did not reveal any studies specifically related to this topic. As mentioned previously, most students take a number of factors into account when determining where to study, so this type of policy change will have a limited impact. However, through the qualitative study proposed here, perhaps some indication of how students view OPT in relation to their educational and career-related decision making process will shed light on the implications of any additional changes to the OPT policy. 


\section{Chapter Three: Research Methods and Data Collection}

For this study, the primary research tool will be a formal, semi-structured interview conducted individually with approximately eight international students. The students selected will have completed a master's degree in a STEM field in the last two years and have begun an Optional Practical Training experience. The interview will be an in-depth exploration of their perceptions, and will consist of open-ended questions. The questions will begin by gathering background information from the participant about their nationality and field of study, and conclude by allowing them to offer advice to other international students and provide any additional information that they feel is important but may not have been covered during the course of the interview. At the researcher's discretion, follow-up questions may be asked at any time in order to clarify a response given, particularly anything that may not be clear because of the participant's English speaking skills. The interview protocol is included as an appendix, and the researcher anticipates it will take approximately 45 minutes to conduct each interview.

The participant will sign an informed consent form before the interview is conducted. With the participant's permission, an audio recording will be made of the interview, and this recording will be transcribed. In addition to the transcriptions of what was said during the interview, the researcher will also make notes during and immediately following the interview. The researcher will attempt to capture the participant's demeanor during the interview. If any questions made the participant uncomfortable or particularly animated, this will be noted. The researcher will also notate his impressions of the participant's English language abilities or other pertinent information. 
If possible, the interviews will be conducted at a neutral site with minimal distractions. If the participant is close to a campus facility, a room in the library or similar space will be reserved. A conference room or other private space at the participant's OPT site is another possible location for the interview, if approved by the employer. However, the researcher will offer to conduct the interview at any location where the participant feels comfortable, including a home or public location, as long as the noise level is conducive to recording. The interviewer will attempt to establish trust with the participants by going to a location of their choosing, and conducting the interviews in a one-on-one, face-to-face format where the participant's comments will not be heard or judged by others.

Before the interview begins, the researcher will inform the participant both verbally and in writing that participation in the interview is entirely voluntary, that they will not be identified by name or in any other way when the data is presented, and that all of their answers will be kept confidential. They will be allowed to withdraw from participation at any time during the interview or afterwards. After the interviews is transcribed, the participant will be provided with a copy of their transcribed interview for their review. They will be asked to member check the transcript for accuracy, and they will have the ability to comment or clarify their answers if they so choose.

\section{Participant Selection}

Recent graduates of a Midwestern university who are participating in postgraduate Optional Practical Training (OPT) will be asked to participate in the study. Since OPT training takes place immediately following graduation, students typically secure this opportunity in the semester before graduation. Because the university 
continues to support the student's immigration status, the student must apply to the university for participation in an OPT experience. With permission from the university, the researcher will e-mail students who are participating in OPT in the area to request their participation in the study.

The largest numbers of students on OPT at this University come from India, and there are also students from China, Iran, Turkey, and other countries who are currently participating in the OPT program. The exact number of students from each country will be dependent upon which students volunteer for the interviews. However, the researcher expects that the sample population will include 2-3 students from India and China, 1-2 students from Iran, Turkey, and/or Nigeria, and possibly a student from Saudi Arabia, Nepal, Bangladesh, or Vietnam for a total of eight interviews. Based on the current numbers of students from each country, a purely random selection of participants could lead to mostly Indian students participating. Therefore, to ensure a diversity of voices, no more than three students from any single country will be allowed to participate. In addition, the researcher will ensure that students from at least four countries are represented by actively soliciting participants from countries other than India.

Although eight interviews cannot capture the full range of perspectives, it will be sufficient to provide some diversity of responses. Because the interviews will be in depth, the amount of data collected should be adequate to establish key themes. Ensuring that participants come from various countries will be important for the data analysis, as students from a single country are likely to face similar obstacles to success. By attempting to bring a diversity of voices, the results can begin to be generalized to the 
larger international student population and more readily point to areas where future research could be beneficial.

\section{Data Analysis}

The researcher intends to use a grounded theory approach to analyze student perceptions in areas relating to their transition to work, including but not limited to:

1. The potential methods of assistance that the university can provide to international students as they transfer to work (e.g., advisors and career centers);

2. Acculturation issues that international students face when starting their careers in the United States, such as language issues, workplace etiquette, etc.; and,

3. Issues that immigration policies play in an international student's decisionmaking process at the start of his or her career.

These areas are specifically tied to the research questions and the purpose of the study. As the data collected is reviewed, the researcher plans to reflect continually upon how the participants viewed the assistance provided to them by their university, how acculturation issues were presented in their responses, and how deeply immigration policies appeared to influence the participant's answers. The researcher will thoroughly examine the data collected for references to each of these key themes, and review the data as a whole to see if additional themes emerged that were not anticipated in advance.

The data analysis will begin with the transcription of each interview. These transcriptions, along with the notes of the researcher, will serve as the bulk of the data to be examined. The transcriptions will be carefully read and specific responses will be coded to match entries related to the identified typologies and research questions. For 
example, the researcher will examine the data to locate responses that correspond to their feelings about how their university assisted in their acculturation process and code these together; comments relating to whether or not they are using the concepts learned as part of their academic curriculum will be coded together; comments relating to workforce practices that surprised or confused them when they started the position will be coded together; statements relating to specific people who are identified as providing particular assistance to the student will be coded in terms of assistance with immigration issues, employment preparation, or overcoming acculturation issues, and so on.

The researcher will look for patterns and similarities among the data collected from each interview. The frequency of each of the shared responses will be noted, and particular attention will be given to any trends or similarities noted by students across the various nationalities. For example, if similar responses are provided by both Indian and Chinese students, this trend will be noted in the data analysis. In addition, the researcher will look for relationships and themes that emerge from the data collected under each typology to identify ways to summarize the information. The similarities in the manner in which students found their OPT position or frequency with which they identify a particular challenge in their transition process will be summarized and generalizations will be drawn from this data.

Themes may emerge that are common across the participants regardless of their country of origin, but the researcher will also look for themes common to specific countries, particularly if there are multiple participants from one country. Similarly, the researcher will look for commonalities that might emerge depending upon if the participants are male or female, and the English language abilities of the participants. 
While the researcher will not have access to, or request specific information about the participants' English language abilities, this will become apparent in the interview and noted in the researcher's field notes. It is likely that the participant's national origin will have some impact on their language abilities, as Indian students are often exposed to English at a very young age, and English is generally the language of instruction at universities in India, but this is not the case for other students. It is likely that Indian students will have a greater comfort level and ability to function in English than their counterparts from other countries. These types of differences will be noted by the researcher and taken into account during the data analysis.

The researcher will create generalizations based upon the patterns and themes identified in the data and will also identify any contradictions or exceptions to the general patterns. Excerpts from the interviews will be identified to support each of these generalizations. While many of these quotes will be descriptive statements about the types of assistance received or of the opinions of the participants, these excerpts should demonstrate the general interpretations that the researcher has gained.

\section{Validation Strategies}

Detailed descriptions, including numerous specific quotations pulled from the interviews, will be provided so that the conclusions drawn in this study can be easily analyzed for validity. A thick, rich description will be provided in the narrative text that will pull information from the researcher's notes as well as the interview transcripts. The themes that are developed from the data will be triangulated by drawing examples from the responses of multiple participants. Any specific examples which counter these themes will also be noted in the description. 
The transcriptions of each interview will be checked carefully for accuracy. In addition, the researcher will contact the participants via e-mail after the transcriptions are complete to allow for member checking of the data. Participants will be have the opportunity to review the transcribed interview and provide any additional comments or clarification. This will help to ensure accuracy and give the participants a chance to add any additional information that they may feel was missed during the interview. Finally, the researcher will review the coding of the data and themes developed against any personal biases he may have as an international education practitioner.

\section{Potential Ethical Issues}

The potential for ethical issues that may arise out of this study is relatively small. The interview process is only seeking to gain the perspective of recent graduates, and involvement in the study should have no negative impact on the participants. The plan to utilize students who have already graduated is designed to allow them to speak freely about the institution from which they received their degree. Since their degree will have been conferred, they will no longer be beholden to professors for grades and the institution cannot deny them their degree for the answers that they give. Some international students may be distrustful, since their legal status is an invited guest in the country, and their visa can be revoked without reason. This can impact them while they are on OPT, and a student could worry that if they do not speak well about their employer or educational institution, they could be sent home.

Some of the individuals participating may hope to secure a long term work visa in the country. As discussed previously, this could cause the participant to feel that he or she must provide the best or "correct" answers to the questions, so as not to jeopardize 
this possibility. Asking these individuals to elaborate about their intentions to work in the United States could present an ethical dilemma for a participant who is concerned about their immigration status. The researcher will attempt to mitigate these concerns by reassuring the participants that all responses will be kept confidential. However, it is important to recognize any potential concerns of the participants and how it could influence their responses and impact the data collected. The researcher shall attempt to remain cognizant of this issue during the process.

\section{Role and Background of the Researcher}

The researcher currently serves as the Director of Graduate and International Admissions at a university located in a suburban area of the Midwest. The university offers a wide array of master's level programs, including a significant number in the STEM fields, particularly engineering, computer science, information systems, biology, chemistry, and environmental science. The researcher plans to use a population of convenience from his institution. The primary responsibilities of his position are related to the admission of new students, and so his day to day responsibilities do not involve frequent direct contact with students currently enrolled at the university. Obviously, there is some contact with international students and the offices which serve them, but he does not serve as an international student advisor, nor is he a Designated School Official with immigration related responsibilities.

The researcher's position and responsibilities will need to be fully disclosed to the students who are interviewed. It is possible that his position at the university will cause some individuals to worry about disclosing certain information or offering negative opinions to him. His responsibilities, however, are not directly linked to their 
experiences at the university or to their immigration status. Hopefully this will provide sufficient distance so that the participants will feel comfortable providing honest answers. The students will be notified that their identity will be kept confidential, and that there will be no immigration consequences from participating in this research.

The researcher was born in the United States and has only worked in this country. He does not have any first-hand experience seeking employment in a country that he is not a citizen. He has, however, worked on programs and projects with international students for approximately eight years. During this time, he has participated in numerous training programs, conferences and other activities to gain knowledge of acculturation issues that international students face while in the United States.

Finally, the researcher acknowledges that as part of the enrollment management team at his university, he has an interest in ensuring that international students choose to study in the United States. He has been part of many efforts to ensure that international students feel welcome and have access to the resources needed to succeed. These experiences can influence how the answers provided by the participants of the study are perceived, especially during the data analysis. It will be important to use direct quotes in the analysis to ensure that the voice of the participants is acknowledged fully, and that the results reported are an accurate reflection of the intentions of the participants. With careful attention, the research should provide valuable insight regarding the perceptions of international students trained at U.S. institutions, as they begin their professional career. 


\section{Chapter Four: Analysis of the data}

The data collected during this study is intended to provide insight into the decision making process of international students early in their careers. The study looked at a specific subset of international students, those who had completed a degree in a STEM field and were participating in the Optional Training Program. Three research questions were designed to guide this qualitative study:

1. How do these students perceive their transition from academic study to work in the United States?

2. What factors do they identify as having the greatest influence on their career path decision-making process?

3. How do U.S. immigration policies, which allow for OPT after graduation, impact the early career path decisions of international students in the U.S.?

The first two questions examine the students' perceptions of how smoothly they transitioned into work, and the types of problems they encountered early in their career. The answers to these questions can help identify the assistance that these international students may need to be successful. Universities currently provide many services to their students and graduates to help them be successful in their careers, and by understanding which services are important to the students, colleges and universities can decide how to allocate resources to ensure the greatest assistance to these students.

The third research question places this discussion firmly in the area of policy analysis relating to both education and immigration. The question hypothesizes that policies relating to the OPT program will have an impact on the career decisions of the 
students who can participate in this program. Understanding this impact has important implications for universities and policy makers alike.

\section{Discussion of Data Collection Process and Participant Characteristics}

This chapter will present an analysis of the data collected, but before this can occur, a discussion of the data collection process is warranted. The International Affairs offices at two Midwestern universities agreed to assist in contacting students who were currently on OPT to participate in this study. Initially the researcher planned to utilize graduates of a single university, but the number of students who met all the criteria for participation was smaller than anticipated at that institution. When it became clear that it would not be possible to find a sufficient number of participants, an additional university agreed to assist. The two offices sent an introductory e-mail, written by the researcher, to students who had graduated with a STEM related degree and were currently participating in the OPT program. The e-mail provided the researcher's contact information and requested that the students respond if they were willing to participate in the study. No compensation or incentive was offered to the participants.

Interviews were limited to a face-to-face format. This limitation restricted the number of students who could participate to those working in a 100 mile radius of a single metropolitan area. The interview protocol can be found in Appendix A. Participants were given the opportunity to choose an appropriate location for the interview. Most chose to meet in a public location, generally a coffee shop or casual restaurant, although one of the individuals invited the interviewer to his home.

An audio recording was made of each interview, and observational notes were taken as additional data for analysis. All interviews were conducted in English. Two of 
the eight individuals interviewed brought a friend with them, but these individuals did not speak during the interview. Generally, a quiet location was chosen, however, because many of the interviews were conducted in public locations, some background noise is heard on the recordings. Very rarely did this cause any data to be lost, but due to the fact that participants spoke with an accent, a few words and phrases in the transcriptions are listed as inaudible or unintelligible. This occurred no more than once or twice during any particular interview. Each participant received a copy of the transcript and was asked to review it for accuracy and to provide any additional comments. Although most of the participants acknowledged receipt of the transcript by e-mail, none chose to correct or update any of the material.

The interview protocol consisted of twelve open-ended questions. Frequently follow up questions were posed for clarification purposes. The shortest interview had a recorded length of 20 minutes and 52 seconds, while the longest was 59 minutes and 19 seconds. On average, the interviews lasted just over 36 minutes. None of the participants appeared hesitant to answer any of the questions, although sometimes their responses were slightly off topic. When this occurred, the researcher tried to ask follow up questions to get a more complete response. In every case, the interviews went smoothly and the participants seemed willing to share their experiences and thoughts on the subject matter. Language was not a barrier, although on several occasions the interviewer had to ask for clarification from the participant regarding a specific word or phrase used. In each case, this was due to variations in pronunciation and were cleared up quickly.

All of the individuals interviewed were male, and English was not the first language of any of those interviewed. However, some came from areas where English 
was common, such as India, and English may have been the language of instruction in their undergraduate program. None of the students had difficulties communicating in English, and the researcher felt that all of them could be considered English proficient.

Six of the eight had completed a master's degree, while one had only completed his bachelor's degree and the other had completed a PhD. Four individuals had degrees in Mechanical Engineering, two in Civil Engineering, one in Computer Science, and one in Computer Management and Information Systems. All of these majors are designated as STEM degrees and qualify for the OPT extension under U.S. immigration regulations. Three of the participants came from India, two from Iran, and one each from Nigeria, Haiti, and China.

The universities did not provide direct access to student contact information. Instead, the International Affairs offices at each university forwarded prepared e-mails to potential participants on OPT. While the original intent of the researcher was to interview only students who had completed a master's degree, two of the individuals interviewed did not meet this criteria - one had only a bachelor's degree, while the other had a PhD. The researcher was not aware of this when the interview was scheduled, and only came to learn of their background as part of the interview itself. As the data collected from these two interviews was still relevant to the research questions, it is included in the findings, but a discussion and acknowledgement of possible implications is discussed when appropriate.

Students who complete either a bachelor's degree or a $\mathrm{PhD}$ will spend more time in the United States before starting their career than those who spend two years or less to complete a master's degree. Additionally, differences in degree types may present 
differences in the student's ability to find employment. These differences have the potential to impact the perceptions of the students, and therefore, could influence the analysis of the data and the conclusions reached. The data was analyzed keeping this distinction in mind, and the issue is noted in the analysis and discussion below.

\section{Observations Made during the Data Collection Process}

Each participant seemed willing to talk about their experience with the OPT program, and the university attended. Some of the participants were cautious with their answers and did not wish to say anything offensive about the school they attended or their employer. None of the participants seemed nervous during the interview.

The investigator did observe that in several instances, the answers provided at the beginning of the interview were brief and fact based, whereas later questions were answered in a more opinionated manner. For example, an early question in the interview protocol asks about the challenges of the student's OPT position. When answering this question, one participant spoke about the complexities of the rules surrounding the OPT program, and another spoke about how managing people was difficult. However, in each case, the answers did not express any opinions about their challenges. Later in the interview, however, when asked to give a specific example of a challenged they had faced, these same individuals answered with personal feelings. One talked about how the rules made him feel that being on OPT is a 'risky' and 'unstable' situation, and the other talked about how it was not a 'happy feeling' to have a company not want to hire you because of your immigration status. This movement from technical language to emotive language seemed to indicate that the participants got more comfortable and less defensive or cautious as the interview moved forward. 
No other significant observations were made. One student work a t-shirt with an American flag on it, perhaps consciously. In some cases, the participant's religious affiliation was reveled either before the interview began or after it was over. While a participant's religious affiliation could potentially influence responses, the researcher made every effort not to bring political, religious, or other cultural biases into the interviews or the analysis.

\section{Identification of Themes in the Data}

The interview protocol was designed to illicit responses from the participants about their experiences at the university and on the job, as well as their thoughts about the OPT program. The questions were also designed to have the students engage in a personal reflection on their transition from being a student to an employee in the U.S.

Using a grounded theory approach, the researcher listened to the audio recordings and reviewed the transcripts of these recordings carefully to identify common themes discussed by the participants. Five major themes emerged as the broad categories that dominated discussion during the interviews. The themes that emerged from the data collected were:

1. Opportunities - Discussions of the opportunities provided by the OPT experience for learning and career development, as well as any other benefits to the student.

2. Regulatory Issues - Discussions of how the rules and regulations of the OPT program created problems or limitations for the students.

3. University Roles - Discussions of how the student saw his university as assisting or failing to assist in preparing him for work 
4. Employer Perceptions - Discussions about U.S. employers in general, the student's employer in particular, or the work environment in the U.S.

5. Cultural \& Personal Issues - Discussions about how the student's culture or individual traits contributed to their career development

Important ideas emerged within each of these themes, and the transcripts were coded to identify these ideas. Every transcript was carefully searched to determine if each idea had been mentioned during the interview. The complete list of ideas identified during the analysis, and an indication of which students discussed each of these ideas, is included as Table 1 in Appendix B.

The data was cross-checked to see if any ideas were universal to participants who came from a particular country, majored in a particular subject, or studied at the same school. If the participant had clearly indicated their desire to remain in the U.S. for their career, or to return home, this was also considered when analyzing the data. Finally, the answers were reviewed to make sure that the responses from those students who had only come to the U.S. for a master's degree did not differ significantly from the two students who had spent a longer time in the U.S. working on a bachelor's or doctoral degree.

The remaining sections of this chapter are a discussion of each of the identified themes. Multiple excerpts from the interviews are included in each section to demonstrate how the participants expressed their thoughts regarding each of the identified themes and important ideas. Quotes are provided from all eight participants.

As mentioned, a complete table containing the full list of ideas is found in Appendix B. This table has been broken down into five parts relating to each of the five themes, simplified for clarity, and labeled as Table 1A-1E. The relevant portion of the 
table appears at the start of the discussion of each theme in order to provide an overview of the main ideas discussed within that theme. Ideas mentioned by 7-8 participants were considered common; those discussed by 5-6 participants were considered typical, and ideas discussed by 3-4 participants were considered variant.

\section{Theme 1: Opportunities Provided by the OPT Program}

Possibly the most important theme found throughout the data is that the OPT program provides numerous opportunities to these students. The first and most frequently mentioned opportunity was to gain work experience, but the students also frequently mentioned the opportunity to network with professionals in their field. Some of the students discussed the opportunity to make money as part of the program.

The main ideas expressed when discussing this theme, and the number of participants who mentioned this particular aspect of the theme during their interview are as follows:

\begin{tabular}{|lcc|}
\hline Table 1 A & & \\
Results for Theme 1: Opportunities & & \\
\hline Key Idea: & Number & Frequency \\
\hline Opportunity to gain work experience & 8 & Common \\
Opportunity to gain practical knowledge or experience & 7 & Common \\
Opportunity to increase technical knowledge / enhance & 6 & Typical \\
education & & \\
Opportunity to network & 6 & Typical \\
Opportunity to earn money / financial benefit & 4 & Variant \\
The opportunity was critical to complete education & 3 & Variant \\
The opportunity demonstrated the student's achievement & 3 & Variant \\
\hline
\end{tabular}

\section{Opportunity to gain work experience.}

The participants discussed how OPT provided them with an important opportunity to gain career-enhancing skills. Every participant mentioned the importance of gaining 
actual work experience, and they frequently mentioned how this complemented the academic credentials they had received. Gaining work experience was important regardless of whether the participant may have had experience working in their home country before coming to the U.S. Seven of the eight specifically mentioned that they had gained practical skills, such as time management or supervisory experience, on OPT but not during their formal education. Some of the participants went so far as to state explicitly that the OPT program was critical to their education. They expressed that without it, their academic degree would be worth considerably less to them. These students also connected their OPT position with the ability to demonstrate personal achievement to their families and potential future employers. One student explained it this way:

I wanted to work [in the U.S.] once I [was] done with my graduation. I know I did work in the past, but working here in the U.S., especially with the technology and the kind of ... opportunity. It [the U.S.] is known for opportunity. So, I did want to apply my courses and find a job that I could work and see how much / how well I learned, and [see] if I can contribute to the company where I am working. And to keep myself updated. ... When I go back to my country ... I would like to go back with the strong feeling that I have achieved something and I have done good for myself. So when I go back I can do better, and I can hire in a big corporation. This is what I see. (Student II)

Another student summed up how OPT adds to his education by simply saying, "I have learned a lot this year and maybe more than I had learned during school." (Student 
I) Later in the interview he reiterated this point by saying "every day I have learned a lot of things at work. So, I would say that all of them are valuable to me." (Student I)

One student expressed his appreciation for the OPT experience by stating, "it makes me feel achievement. I have achieved something that other people have never done before. That is a very good feeling." (Student VIII) This particular student's OPT position was only temporary, however, and he went on to describe why it was important to him to find a long-term position while in the OPT program:

So if we [he and other students that do not have an OPT position] come back like this, without any working experience and we have no idea what is going on in the field, and we don't know anyone in the industry, I think it will be very hard for us to grow up in a career. So, I want to get a job and get experience here before I get back to [my home country]. (Student VII)

When asked why he was participating in OPT, a student talked about the technical knowledge that he hoped to gain:

"I wanted to get industrial experience in CFD [computational fluid dynamics] in the U.S. because, speaking honestly, my goal is to go back [home]. So, while I am here, I want to learn as much as possible ... by working in my field. And so I definitely want to make use of OPT. So, the main reason was to get industrial experience and to get experience of life in the U.S. ... initially my plan was, like, I will complete my masters and then I'll go back and work there in my home country. But as I graduated, I thought, there are a lot of opportunities coming up, so why don't I grab them and utilize them with my OPT? (Student IV) 
This same student expressed that by working on OPT he had learned skills that he did not possess before he came to the U.S. He noted that:

Before I was, kind of like, a single person, an individual person. But now I, like, I have moved into a teamwork-oriented perspective. So that, like, I can use it in my future career. And also, yeah, mostly time management and, um like having, like, dealing with different types of people. (Student VI)

When asked to identify something valuable about the OPT program, one student stated:

So basically here was a good thing - right after my graduation, I was not kicked out [of the country], right?! And, so, I had a job opportunity that was waiting for me immediate. So, there was no delay, right. It happened right after my graduation. That process was very smooth and very helpful, so as soon as I applied I got an opportunity to work for a year. And then that was one good thing that I really appreciated. ... The whole OPT program, where [before] the job is sitting for you and you couldn't take it, now you can take it.” (Student II)

\section{Networking opportunities.}

Six of the eight mentioned the importance of improving their network in the industry as a key benefit of participating in the OPT program. One mechanical engineering student mentioned that he felt his education was not complete without this possibility to grow his network. He noted that in the classroom:

I can only learn part of the field ... what is going on in the field, in the manufacturing area. ... But if I talk to many people, I will know more about it, 
and I will know what is the cutting edge technology and what is the most popular stuff, so I can head in that direction." (Student VIII)

Another stated that the most valuable part of his OPT experience was how he had learned from being in contact with different professionals during his OPT experience:

The engineers from different companies, they have different experience, different ages. I have learned a lot of things from them. Some of them are traditional and I love their ideas. And some of them are young engineers and they just want to do it fast, and using their computer programs, and it is a different experience talking to them. So I would say, all of them are valuable for me. (Student I)

\section{Financial Benefits / Opportunities.}

Half of the participants discussed the financial opportunity provided by the OPT program. The students are able to earn a significant salary while on the program, and this helped them to feel that the cost of their education in the U.S. was worthwhile. Some participants spoke about being able to assist their family financially after having been supported by them for so many years.

This is one important thing. Being an international, you spend a certain amount of money, you have to pay a lot of fees ... So if you spend like, maybe $\$ 50,000$, to get your master's degree, so you work for a couple of years or so and you gain the experience, and at least you earn what you spent. And then go back with zero to pay ... So, you don't have any debt or loans, so you clear out the loans and go back. (Student II)

Another student said simply "it gave me money ... I mean, I know for some people it is not important. But even though my parents supported me and I didn't have 
any debts or anything like that, it helped me a lot." (Student IV) He went on to note the high cost of education in the U.S. and indicated that if his fellow international students are not allowed to work "it doesn't make sense for them to spend so much money and get a degree and just have to go back immediately."

Two of the students confirmed that at least some of the money they receive from their OPT position goes back to their home to assist their families. One stated that "my family back home is benefiting, and I am living good, and I am sending money back home and I am making sure things go on." (Student III) Another stated "I am here and I support my family back [in my home country].” (Student V)

These students all successfully found employment related to their field of study through the OPT program, and as might be expected, their comments demonstrate that they recognize the opportunity that has been provided to them. This theme captures the most positive perspective on the OPT program revealed in the data. The remaining themes bring into focus some of the challenges these students face when beginning their career in an OPT position.

\section{Theme 2: Problems and Limitations of the OPT Regulations}

The second major theme to emerge from the data related to the OPT program regulations. The students feel that the program is complicated, that it causes confusion, and that it places limitations on a participant's career options. In addition, the current political rhetoric about immigration policies, has left participants feeling uncertain about the program and in some cases anxious about their future. The main ideas related to this theme are as follows: 


\begin{tabular}{|lcc|}
\hline Table 1 B & & \\
Results for Theme 2: Regulatory Issues & & \\
\hline Key Ideas: & Number & Frequency \\
\hline Regulations are complicated to understand & 8 & Common \\
Uncertainty surrounding regulations & 6 & Typical \\
Regulations limit the student's options & 6 & Typical \\
Regulations cause confusion & 5 & Typical \\
Regulations cause anxiety & 3 & Variant \\
\hline
\end{tabular}

\section{Complicated and confusing rules for students.}

All of the participants discussed how complicated the policies relating to OPT participation were. Participants indicated that they learned about the program only after they had arrived in the U.S. and their understanding of it was informed primarily by what happened to them personally. They used their personal stories to demonstrate the complexities of the program and the confusion that it caused for their employers, their classmates, or themselves. While most of them stated that their university's international office helped them to navigate the program, a few indicated that they had researched and learned about the program themselves.

"It is a complicated process to, like, apply for the OPT," said one student, “complicated forms, and, like, preparing the documents." (Student I) He went on to talk about how potential changes to immigration policies is a concern, as it seems to be "getting harder and harder. It makes me nervous." (Student I)

Another student spoke about how even the university offices seemed to be confused about some of the rules and how they are applied. The student indicated that the university had caused additional confusion when he tried to apply for a job before he was finished with his research at the university. He stated that: 
There was a lot of confusion for that. ... The rule is that you get done with courses and then you have the right to go ahead, but then they are going to restrict you ... and they want to keep you on campus as much as they can to get work out of you, you know? So I got a problem with that. (Student VII)

Another student discussed how the complexities of the program caused international students to consider working around the regulations, but he did not agree with this approach and had this advice for others interested in OPT:

Follow the process. Don't take shortcuts. That is very important. Don't work on campus without proper authorization. And it doesn't matter ... no matter how good it sounds -- the job you could get under the radar -- don't risk it. Because if you risk it, then you risk your future in the U.S. (Student V)

\section{Complicated regulations discourage employers.}

The most common complaint expressed was that employers were not interested in hiring international students on OPT. Several students mentioned that it seemed to be getting more difficult to find an OPT position in recent years, and they blamed the restrictive nature of the program and the current political climate in the U.S.

I think that they have made it more stricter. So I know for a fact that when I talk to my friends many of them are facing difficulty finding a position. Just because, you know, they will need sponsorship in the future and employers don't even want to get into that, so I think for me it is a worrying trend for students, for future students coming to the US. (Student IV)

Another student discussed his difficulty when talking to employers at a career fair held at his university by stating: 
I got a couple of interviews, but it didn't work out well because, like, they didn't want the international students. So, they don't really say that, but they ask 'hey, do you have green card? Do you have passport?' and when I said no, it was a problem. (Student I)

Later in the interview, he contrasted the difficulty in getting employers to hire him with the perception he held before arriving in the U.S. that finding employment would be easy:

When I was back home everyone just told me, you come here and study a few years and you'll get your green card, and you can teach in school and it is pretty easy. Yeah, but when I got here it was like, no, this is not what I thought. It is much harder. It is doable, but it is hard. ... I thought I can easily find a job. But it wasn't that easy, it was harder than I thought. But now, my main problem is my immigration status. Now I have a job, but the problem is immigration. (Student I)

\section{Career path limitations.}

Finding an employer willing to hire a student on OPT was not the only problem these students discussed. The complex rules often influenced their decisions. One student discussed how the 90 day time frame to find an OPT position complicated his choices:

I was deciding between going for a PhD program or applying for a job. I was too nervous to go for a job because, with OPT you have just 90 days to find a job, and if you couldn't it is going to be so complicated. So I was so nervous. I started applying for a job, but a lot of companies won't do the sponsorship for H1 visa, so 
I really tried to get so many jobs. So, and I was thinking about going for a $\mathrm{PhD}$, but it was like five years and I didn't want to study five more years, so I thought I would go with a job. (Student I)

Although OPT regulations allow a student to change jobs while participating in the program, students express a reluctance to do so because of their immigration status. They did not trust that a change in status would go smoothly. Rather than risk the possibility of losing their eligibility to work, they often stay with a company even if they do not like the position or if a better position becomes available. One student spoke about turning down a possible new position in this way:

You don't have that much freedom. Ok? So when the company is going to apply for your immigration, then you should stay over there, with whatever situations are over there. OK, so I actually got a interview with [a] university in West Virginia to become a tenure track faculty. And I was approved for the first term, and I was approved for the campus interview, but simply I didn't... I wrote them and declined it, going there, because my situation was not clear, and um, I am under OPT working for this company, and they are applying for the green card, and so I should stay here as long as I ... at least until it is clear what I am going to do, and what is going to be my situation. ... And then because it is a short period, if you find a difficulty with your current employer, then one option is just leaving and finding another job, but it could take 6 months or 7 months and already your OPT is going to be gone. (Student VII)

Students feel that these limitations, real or perceived, put them at a disadvantage compared to their American co-workers. They feel that they could not change jobs or 
pursue other opportunities out of a fear of losing their immigration status. One student noted that at his job “there was an American, he didn't like his position, the location, he left. I didn't have that option. I couldn't just wake up [and leave].” (Student III)

Another student expressed how he felt highly qualified for available positions, but lost out to less qualified individuals because of his immigration status.

I have seen citizens, green card holders, get along with it-- who may not be that much eligible for that job, right? And I am not saying that they are not talented or something, but the job is more relevant to you than someone who is learning from scratch. And the company wants us, but there is this restriction, that is hurtful, because you have lost a very good opportunity, a golden opportunity. (Student II) The students did not necessarily blame the employers for this problem; rather, they seemed to recognize that the employers were placed in a difficult situation because of the regulations. Nevertheless, they expressed feelings that they were negatively impacted by the restrictive aspects of the OPT program.

The difficult thing is that, so, it is temporary. And you should think about your future. If you want to go back home or go outside the country, and there are several uncertainties about the immigration in the U.S. And, um, for the person who is going to be on the OPT, he should just think about what he is going to do after that, because it is just a temporary position, you know? (Student VII) Another student expressed it this way:

How do you convince a company? 'Hey, I am qualified, but I have this program that is good for two years, but I really don't know what happens after two years?' So I really don't know, I think that is where the discussion comes in. ... What is 
the promise to the company? Because when you think about it. It is not fair to the company ... that wants you. They just don't want someone to come and you get good and you leave. Because they are going to impart the knowledge in you. It is going to take two years before you even know the job, and you start applying ... and you know, being a part of the company. So you wouldn't blame the company for not trying, to say, 'no, don't do OPT.' ... They just don't want to do it because it feels like a temporary thing. So I don't know if ... some sort of image change has to be done to it, but it [the OPT program] is something that is not that attractive to most companies. (Student III)

One student also spoke about the rule that OPT students must work only in their field of study. He was not opposed to this rule, but was concerned about how strictly it could be applied. He felt that it impeded his ability to pursue other areas of interest in his life.

So I like to work on other things too. I really like writing, you know writing fiction, non-fiction, so that is my main passion.... But the OPT, basically, you cannot do that. Because you should do whatever you have studied at the school. So that gives you a restriction, even when you want to write, maybe just write a column for just a web blog, or for like a newspaper or on line magazine. You don't know if it is OK here or if it is not OK. Because it is just a voluntary, like just for fun, like hobby, ... like maybe it is going to be tricky, because they say, 'no this is work, not a hobby.' So this is very, kind of tricky point, turning point. So for this reason I actually ... don't want to go beyond the red line. ... I don't like it, but I somehow restricted my writing activity, you know. This is my passion, 
but I have to not doing that because of this. Moreover, I am not going to like use it for being paid for that or my first job, but I want to do it for hobby. And still doing it as hobby, you don't feel comfortable. (Student VII)

This quote illustrates how the students are very conscious of their immigration status, and how confusion over the regulations seems to impose limits on them. Their life choices are limited by a concern that they may break the rules, and the perceived consequences for breaking these rules.

\section{Uncertainty about the future of the OPT program and U.S. immigration}

\section{policies.}

The potential for the rules and regulations to change at any time was clearly a concern for many of the participants. The new president and administration in the U.S. was mentioned on several occasions as increasing the uncertainty around the program. When asked if he had concerns because of the new administration, one students said "yes, huge, especially now with the new changes. I don't know, the Trump effect ... but what can you say, I mean, what he is doing definitely ... it gives a difficult ... it puts students in a difficult position. To be frank, it is a symbol." (Student II) The student lamented about how difficult it was to convince an employer to participate in the OPT program. He noted that his friends who were looking for a position, "took more than six months, and close to one year, and still they didn't get an OPT. And I have friends who didn't get an extension. It really effects your career. (Student II)

Another student explained it like this:

The other challenges are uncertainties about the status of OPT, because after the new administration came, so there were several news [stories indicating] that the 
new administration is going to change the rule or finalize the OPT or remove it. So you are always are in kind of a weird ... so even now, five months later, I don't know what is going to happen, you know? So this is another uncertainty. Yeah. (Student VII)

He summed up his thoughts elsewhere in the interview by stating simply "So basically the OPT is a kind of an unstable situation." (Student VII) But he was one of the few students who mentioned the importance of the STEM extension.

This three years gives an abundance of opportunities for people to find out what they are going to do. These three years most of people either apply for H1B or green card or going to another country, but for those who are not a STEM, so they have just one year OPT, so most of them, because that one year is not enough time for being settled, right? ... [The two year extension] makes more possibilities for your career. (Student VII)

When asked to comment on the OPT regulations, the students were mostly negative about the limitations of the program. This is quite different from the positive impressions mentioned in the previous theme. Opportunities were discussed when the students were asked about their individual OPT position, while limitations were discussed when referring to the program in general. The data clearly indicates that students find the OPT rules complicated, and they are concerned that immigration policies can easily change. These factors cause them to feel uncertain about their future and their decision to start their career with an OPT position in the U.S. Students mentioned the key ideas in this theme with common or typical frequency. The next theme, however, produced a variety of ideas expressed less frequently, but were still significant. 


\section{Theme 3: University's Role in Preparation for Employment}

The participants expressed a wide variety of ideas about their time at the university. All spoke highly of the education that they had received, although some indicated that their program needed more focus on practical skills. Generally, these students felt prepared to step into the work environment from a technical perspective. Several of them indicated that the university had helped provide them with additional opportunities, such as a teaching assistantship, a chance to conduct research, or an internship position that was particularly helpful to them at the start of their career.

Typically, they spoke highly of the work of the international office at their university, but their views on other services provided were mixed. Some felt that the career center and student support services at the university were helpful, while others wished that more assistance was available, particularly assistance that would provide them with links to employers. Faculty advisors were viewed favorably, and some expressed gratitude for a particular faculty mentor. Others, however, wished their advisor had done more to assist in their job search. The key ideas for this theme are:

\begin{tabular}{|lcc|}
\hline $\begin{array}{l}\text { Table 1 C } \\
\text { Theme 3: University Role }\end{array}$ & & \\
\hline Key Ideas: & Number & Frequency \\
\hline $\begin{array}{l}\text { University provided relevant technical knowledge through } \\
\text { coursework }\end{array}$ & & Common \\
University provided extra opportunities to gain knowledge & 6 & Typical \\
International office explained rules and regulations & 5 & Typical \\
regarding OPT & & \\
Faculty advisor/mentor assistance & 4 & Variant \\
Career services / soft skills assistance & 4 & Variant \\
Importance of practical job related coursework & 4 & Variant \\
Encouragement to succeed & 3 & Variant \\
Assistance was lacking or problematic & 3 & Variant \\
Need for better links to employers & 3 & Variant \\
\hline
\end{tabular}




\section{Technical preparation.}

Across the board, the individuals interviewed felt well prepared technically by their university for their OPT position. Several students indicated that the work they were doing was exactly what they had studied, and others indicated that their technical knowledge allowed them to be successful immediately in the work environment.

Numerous examples of this idea can be found in the interviews. One students stated, "So I just need a computer to do modeling and it is really kind of like a continuation of what I did in school." (Student III) Later in the interview, he reinforced this by saying, "really what I do now is just like a continuation of my homework with a little bit more strategic, or has more aim. And they pay me for it!” (Student III)

Another student spoke about his OPT experience by saying, "So for me, being a computer science student, it is pretty much what I learned. I am applying here in my job the technologies that I learned." (Student II) He also reinforced this message later by stating, "there were a lot of projects and assignments that we do in college. ... They offer you all the cutting edge technologies, it gives you strong fundamentals ... And I had a project management course, which is exactly what I am doing here, right now ... so I use those techniques.” (Student II)

Sometimes praise for the technical preparation was tempered by a desire for more practical training.

I think the technical - they did an excellent job. I think the only thing that was lacking was the practical side of it. And every time I would go back to the school I would always say, "Please make sure that you teach the students project 
management. Make sure they know CAT, they know SolidWorks, make sure they know that project management is going to be very, very important. And make sure they know how to work with their hands. Because one thing that I have found out is that I could think, I could think and figure it out, but I wasn't really hands on. (Student V)

\section{Extra experiences provided by university.}

Many of the participants discussed how the extra opportunities provided to them at the university assisted in their success. Three participants discussed how their experience as a teaching assistant helped prepare them to be more comfortable working with Americans. Conducting research on campus also gave several students the confidence needed to solve problems in the workplace.

I did different jobs when in school. I was a simulator client, a manager, then I was a teaching assistant and research assistant, so it builds you that professional career. You pretty much get a chance. It is not too professional, but still you are doing the job, managing the people, and you know, students, right? So you are able to directly contribute somewhere. It may not be the same thing that you are doing, but you know, some pieces of it contributes to your success. (Student II) Another student discussed how his assistantship was helpful to his career: While I was a TA I was talking to a lot of American students. So again, that gave me confidence. ... I think that being able to communicate with them and, you know, sometimes teaching them how to do some things, that gave me more selfconfidence and I sort of became comfortable with American culture. (Student IV) 
Internships and on-campus jobs were also noted for assisting students to adapt more easily to the work environment.

\section{Student services and soft skills preparation.}

University services provided to these students were given mixed reviews. Many of them appreciated the assistance that the international office provided in navigating through OPT rules. One student summed it up by saying "the international office was really helpful going through the process of getting the OPT ... they help us a lot, and they are always helpful, really." (Student I) Another stated:

You understand that they [the international office] got your back, and um, I mean they have been helpful since I came to the United States. Even when I was [back home], they were sending me e-mails. The emails were the first sign of 'wow, this might be possible' because you know they made it a little bit personal, like you know. I mean [when I was back home], what do I know? I don't know if I can do that thing, and when someone sends you an email like 'hey, don't worry.' And I am like, really? You know they even called me by my name! ... I think they do it very, a very good job. On that aspect, I think they do a really good job. (Student III)

Others mentioned the importance of career services, such as assistance with resume writing and interview skills.

The Career Opportunities and Employer Relations [office] has, that is very good, is they have the mock interviews... where you dress up as if you were going to interview with a regular employer. And they go through it and they coach you through it and everything and they assess your tone of voice, eye contact... this is 
very important. It is something that every international student should take advantage of... it was very helpful for me... I don't think that I would be able to get my jobs if it were not for that. It just would not happen because I didn't have interview skills before. I mean, I went through this entire two and a half years, I was there every semester -- to the point where I was able to anticipate the questions in an interview, and most of the time I would be right. And then I would know the answers ahead of time. So that was something very good. (Student V)

The perceptions were often very individualized and sometimes mixed. While some spoke highly of the help they had received in this area, others indicated that the assistance felt superficial or insufficient.

I used career services. They updated my CV, and it was good, but not very helpful. It was good, but they just gave me some comments for that. And the international office... no I didn't get anything from there. It was actually more confusing working with them... sorry to say...And the university has a writing center that is good that you can take your writings over there. But on the other side, they don't go into the details that much. They just say "here..." and not more than that. (Student VII)

A student recalling his time at the university stated that the university "actually provided some program, like technical writing and technical editing and a course about it. But I didn't find that very helpful because you cannot teach somebody to write a theoretical article in two hours." (Student VIII) 
The career fairs sponsored on campus were mentioned frequently. Five of the eight students indicated that they had participated in the career fair on their campus, but most found the results to be disappointing because many of the employers who participated would not hire students on OPT.

So last year there is a career fair, and our campus usually provides the company names with what type of people they are looking for. So last year they provided that list and said the companies that will hire international students are marked with a star. But I looked through that list and no companies are listed with that star. (Student VIII)

Later in the interview, this student summed up his frustration by stating, "the career center in our campus, they do provide some service like resume review, and they provide some service for people to borrow the suits. But I don't think that really helps for us to get a job. "(Student VIII)

Another student expressed disappointment in this area as well, saying, "Well, that is a little bit of a disappointment with the university. You know we used to attend career fairs every fall and spring... but the list of employers hiring international students kept going down and down.” (Student IV)

\section{Faculty and advisor assistance.}

Faculty members and advisors were also given mixed reviews. Some expressed great appreciation for the mentoring and encouragement that they received. These students felt that one or more faculty members had gone out of their way to ensure their success. 
All the teachers made me comfortable outside the classroom; they made me understand what the work place should be. ... For example, I have a professor ... and mostly when I went to his office, he reached out to me. He talked to me about soccer. He made me feel comfortable. And just when I am about to leave, he would just drop a point and say 'hey, it was a pleasure to know you from the last class you took, maybe you should do certain things...' And I think that was his way of positive criticism, you know, of teaching you. I will never forget that. You know he could have called me to his office and said, "why did you do it this way, it's wrong,' ... I have to say a lot comes from that, you know, that was a good way of someone reaching out to make someone, to make them feel comfortable, even when telling him his mistakes. (Student III) Another student expressed his appreciation for his advisor and spoke about how the advisor was particularly helpful when he was working on his thesis:

My advisor for my thesis, he was very helpful, even though he was very particular that the thesis should be completed with a high standard, right. I was doing it, but he was supportive ... You know if I was stuck, he would help. And being an international, you always have a problem with writing, so he has gone through my document -- I have wrote a 70 page document for my thesis -- so he has gone through that a few, maybe 20 to 30 times! ... It was very hard, but he was so good with that, so it helped me a lot. And when I was there with that professor I got a chance to do a lot of research, independent research, and you know, he gave me a problem, I had to connect a lot of pieces and come up with a solution. You know 
my thesis was really a very good problem that we tried to solve. So he was helpful and his guidance and mentoring was helpful. (Student II)

Another student summed up his thoughts simply by saying "I think that the university has, like, the best, I think good faculty. Like the professors and all that, they teach very well, in depth.” (Student VI)

The students also recognized that the faculty play an important part in preparing them for their career. They expressed appreciation when a faculty member pushed them to do their best work. One students stated:

Although my advisor was picky and he tried to take as much as possible out of me, on the other side, he was also supportive. So he was the kind of connection for introducing me to this company [where the student is currently on OPT], and also, like... and then he provided different research areas that I worked on them that made a good background for me, for my future job. (Student VII) When asked to give advice to new students arriving in the U.S., one student encouraged them to:

Take the help of your professors. You know, there are always mentors and coaches out there, right. So how much you learn is very important, so once you learn the good things, not just the technical, but soft skills, communication, and participating in all the activates in the school. Make the best use of the school as a foundation for you, for a successful career. (Student II)

Others wished that the faculty would have assisted them more in securing employment. They noted that the faculty were helpful with their academic coursework but did not have connections to help them find a job. One student stated, 
My advisor wasn't really ... I don't know how to say ... in the industry. He just focused on the educational and prepare journals, and he didn't have enough links in industry. But I saw a couple of other professors in the civil engineering department that helped students go with different companies in [the] area. But my advisor, he helped me, but he didn't have enough links in industry to help me find a job." (Student I)

Or in some cases they did not offer the guidance that the student needed to be successful.

So I came to do the research, and I have no idea what research is, so what I should do? And nobody tells me. So I have to do the bi-weekly meeting with my professor alone. So every time I came to his office to report the progress, he was mad at me because I have no idea. And he also is not familiar with that field so he couldn't provide some guidance. So at that time I really wished somebody could have helped me out. (Student VIII)

\section{University connections to employers.}

A majority of participants indicated that they wished that the university support offices would help to inform employers about the OPT program.

I do wish the international office was more proactive in explaining to the employers what is the process of hiring an international student. And it is not complicated, of course they have to sponsor H1B but I think that they should be aware that it is a simple process and then they are free to make their decision. After one career fair I went and spoke with, I think, the director of the career fair office...And I told them that we are not getting positions. Only some of the 
international students got opportunities through the fall and spring career fair, but it was very low number. So I told them you should bring out a document that shows the process of hiring an international student. (Student IV)

Later in the interview this same student spoke about how he would like the university to do more to help them network with employers willing to hire international students. "You know, the university can ... have a network with different companies that usually hire the OPT students. So, you know, tell the students that these are the companies that usually hire OPT nowadays.” (Student IV)

Helping to identify employers willing to hire international students was mentioned by three of the students as one of the best things that the university could do to help.

The most helpful would be if the campus, if they could contact some companies which are willing to hire short term or contract students at entry level would be helpful ... that is pretty much the time you have. So I think that would be a good thing to help the students. (Student VIII)

Regarding the university's role in preparing them for a career, the students unanimously felt that they had received a quality education, but their comments varied regarding specific services and support that they had received while in school. Some of this variance is related to the different personalities and backgrounds of the students. Students who were outgoing in the interview appeared to be more likely to seek out services provided outside of their academic department, but a clear relationship between student personalities and their satisfaction with the services provided could not be established with the data collected. 
Significant experiences provided by the university, such as research projects, teaching assistantships, and internships were recognized as providing important careerrelated benefits, whereas single events or interactions, such as a resume writing seminar or single meeting with a career counselor seemed to offer limited benefits to these students. Overall, the students spent the most time interacting with individuals in their academic department and this is where they found the most benefits.

\section{Theme 4: Employer perceptions}

All of the students expressed their views on employment in the United States.

Generally they spoke positively of the work environment, and some discussed the additional training or mentorship that they were receiving in their OPT position. However, seven of the eight mentioned that most employers did not wish to hire international students because the employer did not understand the regulations surrounding OPT, they felt that the regulations were burdensome, or they did not feel that it was worthwhile to invest in an employee that was only authorized to work on a temporary basis.

Table $1 \mathrm{D}$

Theme 4: Employer Perceptions

\begin{tabular}{|lcc|}
\hline Key Ideas & Number & Frequency \\
\hline Unwillingness to hire international students & 7 & Common \\
Positive work environment & 7 & Common \\
Need information on OPT regulations & 5 & Typical \\
Willingness to train & 4 & Variant \\
\hline
\end{tabular}

\section{Unwillingness to hire international students.}

During the search for an OPT position, the participants overwhelmingly felt that most employers do not want to hire international students. The only participant who did 
not express this was the student who had earned a Ph.D. His advanced degree seemed to open up additional opportunities for this student.

Numerous stories of being passed over for a job or refused an interview were shared. All of these show similar concerns and the stories below speak for themselves: I went for so many career fairs, and um, you try to explain, and most of them [employers] don't know what OPT is. ... you try to tell them it is a government work permit and they are like, 'are you sure?' I keep telling them I have the OPT, and you know, they just... for some people... once they actually hear that, they just don't want to deal. (Student III)

A lot of companies like your skills and see your talent, but they ask you your visa status. So once you say you are on OPT, then your immediate answer is "oh, so we don't do the sponsorship." Right? So that is a very big stopping point for a lot of internationals. So even to me, I have gotten a couple of opportunities, right, so once [they] came to know that I was an OPT, then they stopped the process right away. And they said 'hey, we are not doing that.' You know, I couldn't tell about that, but it is not a happy feeling (Student II)

I find the most challenging is not my background, not what I have learned, so it is my citizenship. So when I give an actual interview, they start with my resume. So I give them my resume and they say my resume looks good, but when we go further, they ask me about my visa status. I tell them I am an F-1 student, and on my OPT I can work for 36 months maximum, and immediately they lose interest. Because they are looking for a full time... or a long term. So they don't want to hire people for only like several months or years. And also after that period they 
have to consider that they have to sponsor the transition to $\mathrm{H} 1 \mathrm{~B}$ and maybe that is complicated, for them it is too complicated. (Student VIII)

Even though you have the skills and you have been working, you are working on OPT and so people would not hire you. They would still invite you for an interview and things like that but they would not hire you. And that was the main reason, was the fact that you don't have a permanent residency, or you are not a US citizen, so it was always the fear that you have to go through all the process of getting a lawyer and everything. ... So that is the biggest challenge, as an international student. If you don't have that job already it is very difficult, especially now, this year, it is very difficult because people just won't hire international. (Student V)

With some companies, straightaway, they will tell you that they will not hire international students period. It is the policy. ... maybe it is unfair to say that they see us differently, but I think maybe ... [well] I don't know their policies ... (Student IV)

Later in the interview, this student related that he thought a job offer was rescinded because of this OPT status:

In fact, I did get an offer from a company in Michigan, but for some reason they withdrew it at the last minute for reasons that I don't know... in the interview I specifically told them that I am an international student and I need H1B sponsorship for continued employment in the future. And they said 'Oh, OK, that is fine.' But you know I was just sent an e-mail that said, I am rescinding the 
offer, or something like that. ..Similar words, and 'Good Luck'. So I tried

following up, but they didn't bother to reply. (Student IV)

\section{Positive view of U.S. workplace.}

However, upon securing an OPT position, the individuals felt that they were treated very fairly by their employers. All but one of the participants had positive things to say about the work environment at their place of employment. They spoke about the opportunities for training and learning from their co-workers and managers, as well as about the relaxed and comfortable environment in their workplace.

Students made statements such as: "First of all, my current position was my dream job, you know ... it is pretty much an interesting job," (Student III) and "So I found this job, and it is a good place to work. It is a good, free environment. Like there is no kind of a dress code or anything. You can go casual.” (Student VI)

One student spoke about how his job may be changing his long term plans, stating that:

Before I didn't have plans to continue working in the US. My plan was to go back to my country after studying and doing research and thesis. ... But you know I really liked working [during my internship] and the working culture was just fantastic. ... I learned so much.” (Student IV)

This student revisited this thought later in the interview when talking about his OPT position by stating:

I mean the offer that I got is very good, and I get good benefits. The company is good. So, the working culture is good. So, I don't have many things to complain... You know, you get nervous, or when you go, 'I need this position.' 
But, you know, the company supported me. My manager, he is a genius ...

Literally, he is. He gave me ideas and he helped me. And always the other colleagues, we have this informal culture, we joke around, it is not formal at all.

Certainly it is a small company, and you know, it's OK. (Student IV)

Working in the U.S. exposed the students to the employment laws and workplace environment in many ways. The students seemed to appreciate this fact and its importance in their careers.

Starting a real job, you know, and that was kind of a turning point in my life. And then I felt that the good thing about that is -- neglecting this uncertainty of the visa and immigration thing -- you are as equal as an American, regards of professional work. So even in my firm, I have a much better position than maybe another colleague who is like engineering technician ... so this equal opportunity I am very interested. So I am right now a kind of engineer, that although I have this kind of visa situation, but these people just work with me as just a regular engineer. (Student VII)

The students had respect for their employers and the environment created in their place of work. Their perceptions were equal parts frustration regarding how difficult it was to find an employer willing to give them a job and satisfaction with the job they were finally able to secure. This theme focused almost exclusively on the students' perceptions about their external environment. The last theme to emerge from the data changes the focus and relates specifically to the students' internal reflections on their personal strengths and weaknesses, and the pressure that they place on themselves as they begin their career. 


\section{Theme 5: Cultural and Personal Issues Relating to Career Development}

The theme of cultural and personal issues relating to a student's career path development is a particularly broad one that is tied together by the student looking inward to examine how his journey is influencing his career. Each of these individuals left their home to study in a new country and had to adjust to a new set of cultural norms. Because of this, it is not surprising that all of the participants mentioned the need to rely on their own personal strength. Their first steps into a career, through the OPT program, seem to have reinforced their belief that they could solve problems and be persistent.

The OPT experience also forced them to realize that the cultural adaptation that may have started with their education was not complete. They cited problems with written and spoken communication skills, and with interpersonal communication issues arising from cultural differences. Almost all of the students mentioned their family in some way. But the influence of the family varied depending upon the individual student.

Finally, their cultural identity also caused these students to put additional pressure on themselves to succeed. They want to prove their worth to their employer and contribute in the workplace - some stating that as a non-citizen they had something extra to prove.

\section{Table $1 \mathrm{E}$}

Theme 5: Cultural \& Personal Issues

\begin{tabular}{|lcc|}
\hline Key Ideas & Number & Frequency \\
\hline Self-reliance & 8 & Common \\
Interpersonal Problems relating to cultural differences & 6 & Typical \\
Pressure on self & 5 & Typical \\
Desire to work or contribute & 5 & Typical \\
Written communication problems & 4 & Variant \\
Ties to family and home & 4 & Variant \\
Other family concerns & 4 & Variant
\end{tabular}


Table 1 E (continued)

\begin{tabular}{|llc|}
\hline Problem solving abilities recognized & 4 & Variant \\
Persistence / Motivation & 4 & Variant \\
Need to prove worth because of status as a non-citizen & 4 & Variant \\
Spoken communication problems & 3 & Variant \\
\hline
\end{tabular}

\section{Self-Examination and self-reliance.}

When reflecting on how the OPT experience has impacted their lives, all of the students indicated that in some way it had made them more self-confident or self-reliant. They recognized that they had learned to solve problems and were capable of succeeding in a work environment. One student's OPT position took him to different locations every few months and he stated "every position that I worked, I actually was able to overcome challenges, whatever it was." (Student V)

They spoke about the pressure that they put on themselves to be successful in their OPT position, and the need to prove their worth in the work place. "My own mantra is, for me, is to be successful," said one student. "I have to be, I have a fear of failing, so that is what has assured me to be successful." (Student III)

Another student confessed that starting to work at his OPT position was frightening to him, but also motivating.

It was scary, but somehow, I think, life ... it makes you resilient, I think. You won't say 'I give up' because you don't know all these things, or just quit and go home. I think, what do you call it... drive? I was scared, but I didn't want to give up. In all honesty, I won't give up. (Student IV)

The fear of failure was mentioned as a motivating factor in respect to being a student and being an employee. As one student explained, "I became scared of failing, so 
I did whatever." (Student III) The student expressed that the pressure or motivation to prove yourself seemed to be amplified by his status as an international student.

I had to prove myself because I am kind of like a conditional student, I am like a student under the government's eye, applying myself. ... I am ready to inconvenience myself a little bit, so maybe that means when I was in school, before when you get a job ... you maybe have to know your engineering a little bit better, because you have to prove yourself. (Student III) And this feeling carried over into the student's OPT position, and he described his motivation at work this way:

If my boss is not satisfied with me, he is going to say, 'he is not doing OK'. So I think that puts you on your toes. I am not just going to relax. I am making sure I am getting experience. I am making sure I get experience at the end. I mean I have to, maybe, work really harder than my peers to prove myself and have a good standing in the system, and that is what I am going to do. (Student III) Another student spoke about the transition from being a student to being an employee as placing additional pressure on him to fit into society. He stated: OPT gives me pressure to push me closer to the society from the campus. So I have to deal with more complex situations compared to the campus. Because on the campus, you know those people, and you just do your own work and you are good. But with OPT, you are out of that environment, you are more uncomfortable. You have to deal with practical stuff, you have to do a tax return by yourself, you have to find a recruiter and talk to him to see if he has an open position. You have to talk to, maybe, somebody working with immigration, to be 
sure you maintain your legal status. So OPT kind of gives me a pressure to do all kinds of things. (Student VIII)

And yet another characterized the pressure to succeed as work ethic and spoke of the importance of having a strong work ethic as a way to protect yourself from the uncertainty of your immigration status.

I think work ethic is very important and you should have the same work ethic wherever you go. Because people are going to see that and they are going to respect that. ... Because being an international student adds that extra stress because you feel that you have to impress every single day. OK? And usually you feel that you can be the weak link ... even though you have the skills and all the knowledge. If they were to cut back or if there were to be a layoff, you would probably be one of the first to go. OK, if it happened, with immigration, you would be one of the first to go. (Student V)

\section{Communication issues.}

Participants spoke about the need to improve their communication skills if they wished to succeed in their careers. They frequently discussed the difficulty that they have in writing reports and completing other written tasks in the work environment. "Being an international, you always have a problem with writing," said one student (Student II). And one stated: "for me personally, it is the first time to write the conference paper. So that involves a lot of very formal and very theoretical, logical language, and English is my second language, so I find that is very hard." (Student VII)

The students became more aware of their weakness in this area, by participating in OPT and having to perform in the workplace. 
What I really struggled with was writing a report because we sent our report to like the IDOT, [Illinois] Department of Transportation, so it should be without any mistakes. You know, it's so hard, I just, I'm just like 3 years studying English and writing English, and it is so hard for me to prepare, I don't know, like a 50 page report and send it to the IDOT without any mistakes. That would be the most challenging for me. (Student I)

"All the activities that I got from school helps with the engineering aspects. But the challenges is interpreting numbers into writing," said one student. (Student III) Later in interview he added:

Grasping the engineering aspect is not so bad, you know, I grasp it quickly since I did engineering for a while - but I have to interpret most of the engineering work into writing. So I have to ... tell the engineers what to do. Most times you find out how a simple word is not as simple as you think. ... they can interpret that in many ways, you know. So I think that I am still learning on the job when it comes to that. (Student III)

But some participants also mentioned problems in spoken communication with their co-workers. Spoken communication issues were mention more in terms of how well the student felt he fit into the work environment. They wanted to get help to improve their skills, but weren't sure that the university could provide this assistance.

I have very big problem in understanding American... what do you call it ... like phrases or when they make their own joke, and I am lost there. So I don't know what is the best way to do that. But if during the masters, there is a way ... if there is something you can learn. ... It is like a kid, right, learning English, so if there is 
an opportunity for internationals to learn the basics so you are not lost and you are included in the discussion, you know. (Student II)

One student discussed his accent at length, stating, "my accent was a little bit different for them. My accent was a complication, it was a little bit challenging at first." (Student III) He went on to relate a story about trying to secure a position and he felt that his accent interfered with his ability to get the job.

One of the guys [he was working with] found out that I had a masters in mechanical engineering, and was like 'oh, I think they got an open position. Why are you doing this? You could do that!' And so I was thinking that maybe I should talk to the boss. And so I spoke to the boss, and the boss already knew I had an accent. And it was a small company, and I said, 'I heard that there was an open position.' ... But he was uncomfortable. He came back and he had to turn the story around and lied and said there is no position. He didn't want to deal with it. He didn't even ask me to go bring my qualifications, so I was like 'was it my accent or something? You can't tell me about the position because I am working on the floor? I can bring my certificate or whatever to show you I am qualified for the job.' So he basically didn't want to consider me. So I don't know how he went about it, if it was connected to OPT, but it was one of the issues that I faced.

(Student III)

\section{Importance of family.}

Research on international students has frequently noted the importance of the family on their educational and career decisions (Shen \& Herr, 2004). Seven of the eight individuals interviewed spoke about their family and the importance of their family when 
making career decisions. For some, the family encouraged them to study and find a job in the United States. One stated simply "my parents always encouraged me to just leave.” (Student I)

But for others the family was pulling them back to their home country for their career.

My mindset was $85 \%$ going back... I have strong family bonds, so at that time, it was not a big concern for me if I won't get a job. ... I want to go back in the next 3-4 years that is my limit. And for sure I won't stay in the US forever. My parents are there, and as I told you, the family bond is very strong. (Student IV) At home ... my father, he is like owning a business there. So I thought that I'd like join his business and use my skills, use all the skills... and go there and work with my dad. It is like kind of a, more of a... I'm like a family person, so... (Student V)

Others simply spoke about the importance of family in relation to their career decisions and the possibility of immigration. Often these ideas were complex, conflicted, or changing depending upon their current situations. One student talked more generally of the idea of immigration and how it influenced his thinking about work and school.

The feelings for every immigrant, the feelings they have, they just want ... a good life. It is something that attracts you here, and so, um... I told my dad, I am going to go. And he said if you want to do that you have to go to school. And so it was ringing in my head -- I didn't want to go to school, I just wanted to come. ... When I got here, I understood. I took education more serious than I ever thought of it when I was back home and my parents were making me go to school. When 
I got here, I understood that I have to go to school. When I got here and I felt, and I saw the difference. (Student III)

\section{Need to be flexible.}

The students were aware that their status as an international student on a temporary visa required them to be flexible when it came to their career decisions. When asked to give advice to new students from their home country, several of the students stressed the need to be flexible:

Focus in your mind that you will do best in your masters to get good grades, and if you get any good opportunity continue with that. Otherwise, I think... there are a lot of opportunities in [in my home country] as well. We can also join so many IT companies there, and also we can run a business or anything. It is not like only opportunities are in the U.S. (Student VI)

I think it is very important to be flexible. I believe that it is very important to be flexible. And, um, also... show that you are willing to work, and not put on a show, but show that you are really willing to work and willing to go the extra mile... I knew that I needed a job and so I was willing to take a [lower pay] just to work for them because I knew I had to be employed, just because of my immigration status. Since I have been working there, they have been giving me more responsibilities because they have seen my work ethic and my work values. (Student V)

The interviews captured students trying to balance a realistic picture of the world with their current status and aspirations. The OPT program was definitely important to them, and they believed it was important for the U.S. too. As one student explained: 
So when I heard about it [the OPT program], I was like, in my brain, it felt justified. Like we go through an engineer program, so like, why don't the system [the U.S.] want to, you know, want to capitalize a little bit? Get something from us, even if it is a little bit? Like, you can't tell me I can come and get all this experience and you just put me out of the country. So I felt justified in my head, it was like, yeah, good thinking, yeah. (Student III)

Another pointed out the mutually beneficial aspects of the program to argue that it shouldn't change, even if other immigration rules, like the H1B visa program, might need to. He argues that it is important for students to gain experience and make some money to help pay off student loans:

A lot of people have good aspirations, and they should be given certain opportunities. And OPT is one good thing...Right, I don't blame them [for changing] H1B, but OPT, at least if they don't touch the policy. At least if they leave them alone to work for three years, that's good enough ... I don't blame them [the U.S. government]... so H1 is a secondary thing, they can take away [that], but you need an opportunity. And OPT is good to learn what you wanted. And you can definitely earn, as well, in those three years. Make some money. Of course you spend what you earn here ... I have to pay like more than $\$ 500$ per month to pay my student loans... (Student II)

Others admitted that their career path is not clear to them at this point, primarily because of their immigration status, and so it is very important for them to consider all of their options. 
Even now I don't have a vision for my next two years. Maybe, ... I just go back, you know? So, because I am telling you that there are several different uncertainties, but this is always, um, pending ... so in the most cases, the U.S. is no doubt better than [my home country's] situation now. So living and staying in the U.S. has kind of advantages, and also has some disadvantages too. Because it is not your home country and you face difficulties and maybe some discrimination too. So it always has some advantages and also some disadvantages too. Those advantages encourage you to stay, and those disadvantages provide you to think of other options, maybe going to Canada or Europe, or coming back home. ... I still have opportunities over there too, you know. (Student VII)

This was one of the few times in the interviews where a student mentioned facing discrimination. Generally, the students were careful not to characterize discrimination as the cause of any difficulty that they faced. Some students hinted at it, when describing how their accent or immigration status may have prevented them from getting a job, but they did not accuse anyone of it in the interviews. Instead, they focused on how their success can be based on a variety of factors, including the ability to overcome obstacles. They recognized the skills that they have gained through their education and OPT work experience. They kept a positive, if somewhat cautious, outlook regarding their career and their future. One student summed up this attitude this way:

Yeah, so mostly, you know, a human usually says good stuff about a particular thing. You know, like behind the scenes, there will be so many difficulties. Like, you know, there are obstacles coming between, and all this stuff. So even I had 
some of the difficulties, but I guess it is like, um, if you have good knowledge and good network and all that, it will be easy for you. (Student VI)

These students view the cultural issues they face in the workplace as a challenge to overcome through their personal strengths. Their time as an international student prepared them for these challenges, and they were keen to demonstrate that they could overcome these obstacles and be successful in their careers. Their status as a non-citizen in the workplace motivated them to work harder, be flexible, and stay positive, even when faced with career development challenges. 


\section{Chapter Five: Discussion, Conclusions, and Recommendations}

The purpose of this study was to understand how international students participating in the OPT program perceive their transition from an academic setting to a work environment. By interviewing students on OPT, the researcher hoped to discover their perspective on this transition and how current immigration policies that allow these students to temporarily work in the United States influence their career path decisions. Little research could be found on the OPT program, even though over 147,000 students participated in the program during the 2015-16 academic year and the program has grown by over $10 \%$ in each of the last five years. (IIE, 2016, Academic Level dataset) This study was designed to help fill this gap in the research on international students by focusing on those who utilize the OPT program to start their careers.

\section{Discussion of the Key Findings}

Each of the themes that emerged from the data provides insights and answers to the research questions posed. Table 2 summarizes the key findings related to each research question and identifies which of the themes support these findings. Key findings for the first research question are the perceptions of the students' transition to work through the OPT program and are characterized as either positive or negative. Key findings for the second research question identify the most important influences on the career decisions of these students, and the influences are characterized either external, or outside of the student's control, or as one that is personally controlled by the student, at least to some degree. Finally, the key findings for the third research question relate to how the OPT program and immigration policy impacts career decisions for these students and these impacts are characterized as positive or negative, or in some cases, both. 


\begin{tabular}{|lll|}
\hline $\begin{array}{l}\text { Table } 2 \\
\text { Key findings related to the research questions }\end{array}$ & & \\
\hline Key Findings & Theme(s) & Characteristic \\
\hline Student perceptions of their transition to work & & \\
OPT provides career development opportunities & $1 \& 4$ & Positive \\
Students are technically prepared for career & $3 \& 5$ & Positive \\
Employers provide a good workplace environment & 4 & Positive \\
Individual's skills and motivation ensure success & $3 \& 5$ & Positive \\
Additional services are needed for transition & $3,4, \& 5$ & Negative \\
Businesses are reluctant to hire internationals & $2 \& 4$ & Negative \\
Career choices are limited by regulations & $2 \& 4$ & Negative \\
Greatest influences on career decisions & & \\
Limits and uncertainties of regulations & $1,2, \& 4$ & External \\
Location of career opportunities & $2,4, \& 5$ & External \\
Technical knowledge gained & $1,3, \& 4$ & External \\
Network (professional and educational) & $1 \& 3$ & Personal \\
Family & 5 & Personal \\
Self-motivation / Pressure on self & $1,4, \& 5$ & Personal \\
Policy impact on career decisions & & \\
Provide career opportunities & $1 \& 4$ & Positive \\
Assist students financially & $1 \& 5$ & Positive \\
Create limitations on career choices & $2 \& 4$ & Negative \\
Cause anxiety regarding future & $2 \& 5$ & Negative \\
Pressure universities to offer additional services & $3 \& 5$ & Both \\
Force students to be flexible in career choices & $2,4, \& 5$ & Both \\
\hline
\end{tabular}

\section{Summary of the key findings for the first research question.}

Not unlike any student who transitions from an academic setting to the workplace, these international students on OPT offered both positive and negative perceptions on the experience. All of the students spoke of their opportunities and their challenges. They recognized the opportunities that the OPT program creates to gain work experience and increase their knowledge, particularly relating to the practical skills needed to be successful in their careers. They also acknowledged the opportunity that their OPT 
position gives them to network with other professionals in their field, to make money to help pay off their educational debt, and to demonstrate their achievements to others.

The students had positive views of their employers, who provide a constructive work environment and additional training to help them to transition into their chosen career. They were mostly positive regarding the university's role in preparing them for the workplace, in particular from a technical standpoint. In addition, finding an OPT position bolstered the student's confidence in their skills. They spoke about their ability to solve problems and be persistent when faced with workplace challenges. They believe that being an international student requires them to work a little bit harder to prove that they deserved the position, but this was generally seen as a positive self-attribute contributing to their success.

Among the negative perceptions was a recognition of their weaknesses. Many of the students still encounter difficulties with their written and spoken communication skills, and sometimes this affects their career. Some students described difficulties with specific tasks, such as writing reports, or an inability to explain things to, or fit in with, their co-workers. Interestingly, this was not mentioned by the student who had earned a bachelor's degree in the U.S. or by the student that earned a Ph.D. These students would have spent a longer time in the U.S., communicating in English, and this suggests that perhaps as English skills improve, these students feel more comfortable working with their American colleagues.

These students do rely the services provided by their university to get their careers started. The university helps them navigate the rules and regulations of the OPT program, and they seek out various career and student support services. Their 
experiences with these services are mixed, however, and the data suggests that sometimes the services provided do not go far enough to provide meaningful assistance. The two most common requests students made were more help to improve their writing skills and more assistance in finding employers willing to hire them. Fortunately, many of the additional opportunities that universities already provide for research, teaching assistantships, and internships are considered very helpful.

These students believe that the majority of employers do not want to hire international students. They attributed this, at least in part, to a lack of understanding about the OPT program. They did not make claims of discrimination, but they did perceive their immigration status as a negative factor in their ability to begin their career. The complexities of the regulations limit their options in both their career and their personal life. Confusion surrounding the program, the uncertainties of immigration policies, and the restrictions placed on non-citizens working in the U.S., all negatively impact these students' career path decisions.

In summary, the students perceived the following as positive aspects of their transition to work:

- The OPT program provides opportunities for career exploration and development.

- The university prepares these students on a technical level in their chosen career field.

- The work environment provided by employers offers a positive atmosphere for these students to begin their career.

- Participating in the OPT program helps students to recognize that they have the skills, talents, and motivation to be successful in their career. 
The students also noted some negative aspects of their transition to work, or areas where they encountered challenges, namely:

- The limitations in their ability to communicate in English, either written or spoken, causes difficulties at times and has the potential to make them feel like an outsider.

- They need assistance in areas such as resume writing, navigating the regulations and identifying potential employers, and these services are sometimes difficult to obtain or are too superficial to have significant impact.

- Businesses are reluctant to deal with the additional regulations of the OPT program, and this limits the students' ability to use the program to launch their career.

- OPT regulations and immigration policies limit the ability of these students to look for jobs, change jobs, or pursue other interests, and these limitations necessarily influenced their career decisions.

\section{Summary of the key findings for the second research question.}

The second research question explored the specific factors that influence the career decisions of international students. Specific rules of the OPT program and the general uncertainty surrounding immigration policy in the U.S. were identified as external factors with considerable influence over the early career decisions of these students. The biggest limitation identified was the length of time that they are allowed to work under the OPT program. Some students recognized that the two-year extension for STEM students was a benefit, but generally, they were focused more on the time limit that would eventually end their ability to remain in their current position. They all understood that the next step to remain working in the U.S. would depend upon their employer's willingness to sponsor them, and even this is not guaranteed if immigration 
policies change. The temporary nature of the OPT program was cited consistently as an influencing factor on their career decisions.

For this reason, many of these students were weighing their options for the future. Options that included returning to their home country, finding a way to remain in the U.S., or looking for opportunities in another country, such as Canada or a European nation. Just as they had found an opportunity in the OPT program, they were looking to capitalize on the next opportunity available to them, wherever it existed. Three of the students indicated that they preferred to remain in the U.S., two planned to return to their home countries, and three were unsure. This demonstrates that the intentions of international students relating to their career choices is not monolithic, but rather complex and individualistic.

The technical knowledge obtained while studying in the U.S. is the third external factor influencing their career decision. This factor is external from the perspective that educational curriculum and research facilities are controlled by the university. It is true that the students did choose the university, and could choose to utilize or disregard the resources made available at the institution, but changing schools or programs is limited by immigration rules. Therefore, the quality of the education they receive is, to a some extent, out of their personal control. Fortunately, this group of students indicated that the technical knowledge imparted to them had a positive influence on their career.

All of the students interviewed were successful in finding employment, and many pointed to a network of individuals who helped them to secure their position. Creating this network was a challenge for these students, but they recognized that it was in their personal control to become involved and build their network. Faculty advisors and 
university career centers were sometimes very helpful, but sometimes they failed to reach these students. However, the extra opportunities for engagement provided by the university, in particular internships, teaching assistantships, and research projects, were cited as very influential.

The students' families were also a key influencing factor. Several stated that close ties to their family made them wish to return home, while others were making their family proud by working in the U.S. Regardless of the direction of the influence, the family was important to their career decisions. However, none of the students made statements indicating that their family was forcing them into a decision. Rather, they appeared to make a personal decision on their career, while keeping in mind their family's wishes for them.

Finally, many of the students spoke of putting pressure on themselves - to succeed, to be flexible, to be motivated. They wanted to be in control of their careers and believed that their actions and attitude was key to their success. Self-reliance was an important career influence.

In summary, several important external factors greatly influence the career decisions of international students participating in the OPT program. Namely:

- The time limitation of the OPT program forces students to view the opportunity as temporary, and they continue to look for the next opportunity available to them.

- The uncertainty of U.S. immigration policies encourages students to consider career opportunities abroad, as well as in the U.S., and often cause students to feel anxious about their future career options. 
- U.S. universities successfully prepare students for their careers, and this should continue to encourage international students to seek higher education in the U.S.

The personally controlled factors that influence the career decisions of international students the most are:

- The ability to set up a network and make connections through opportunities available during their academic career is critical to their success.

- Family will continue to influence the career decisions of international students, but the direction of this influence is individually determined.

- Self-motivation and the need to prove their value in the workplace can strongly influence the career decisions of international students.

\section{Summary of the key findings for the third research question.}

The final research question focuses on the ways that immigration policies can influence the career decisions of international students. Regulations are outside of the control of these students, so the research question seeks to understand how the students react to the existing rules. The data indicates that students recognize that immigration policies can change at any time. This potential for policy shifts brings a good deal of uncertainty into the circumstances in which these students are trying to begin their careers.

U.S. immigration policies, including the OPT program, give students an opportunity to work in the U.S. and this assists them financially. These benefits do not go unnoticed by the students. However, they frequently referenced the changing political landscape in the U.S., and they recognize that the government can change the rules under which they are starting their careers. They know that they must be careful with their 
career choices due the potential for such changes, and the limitations placed upon them by the current rules. If the rules change, their current opportunity could be taken away. This uncertainty caused the most anxiety and was seen as the biggest negative to their participation in the OPT program.

The data collected revealed two additional impacts of the OPT regulations. Because the program provides the ability to work while on a student visa, these students must continue to report to the university they attended. In many ways, this puts pressure on the university to provide employment related services to their international students. Previously, universities had little need to provide career related services to international students because these students were expected to return to their home country to search for employment. Career centers had limited knowledge of job markets overseas, and they were not equipped to provide tools, such as resume preparation assistance or interviewing skills, to students who would be functioning in another culture with different rules and regulations. With the expansion of OPT, particularly since the STEM extension was created, more international students are seeking the assistance of their university to prepare for the U.S. job market. From this perspective, the OPT program is placing an additional burden on the universities to provide career related services to their international students.

Finally, as mentioned in several areas of the data analysis, the OPT program forces students to recognize their strengths and weaknesses as an employee. They learn that they must be flexible to secure an open position, and they must be prepared to work wherever they can find an employer willing to hire someone for a relatively short-term position. This flexibility can be positive, and the student may learn to be adaptable, but it 
can also be negative as it creates additional obstacles for these students when making career decisions.

In summary, U.S. immigration policies relating to international students have the following impacts:

- The opportunity to work in the U.S. as part of their educational experience helps these students launch their careers and provides financial benefits to them.

- The potential for policy shifts cause students to consider all options, including those outside of the U.S., and creates uncertainties for students regarding their career choices and for employers seeking a highly educated workforce.

- U.S. universities are facing pressure to provide additional career related services to international students because of the OPT program.

- The opportunities and limitations of the OPT program require international students to be flexible when making career path decisions.

\section{Conclusions}

The findings from this study support some of the previous research in this field. The data collected clearly indicates that career decisions for international students are complex, and multiple factors influence these decisions, including the decision to remain in the U.S. The results reinforce conclusions drawn in research that was discussed in the literature review. Examples include conclusions made by Popadiuk \& Arthur (2014) that a student's ability to establish key personal and professional relationships impacts career decisions, and by Reynolds \& Constantine (2007) that a student's capacity to overcome language and acculturation issues is an important factor. The data also supports findings by Shen \& Herr (2004) that family ties can influence career decisions; and by Musumba, 
Jin, \& Mjelde (2011) that these decisions are frequently based upon where the best career opportunities are available.

The OPT program is a career development opportunity for international students, and these students seem particularly keen to capitalize on this opportunity. These students were willing to take a risk and come to the United States for an education, and therefore, it should not be surprising that they would want to take advantage of an opportunity to start their career in the same country. But the data also suggests that the motivation to find longer term employment in the U.S. will vary from student to student. They were not monolithic in their desire to remain in the U.S. for their entire career. They were, like most young professionals, still trying to figure out where their career would take them, and what the best options are for their future.

The majority of the students admitted that the opportunity to work in the U.S. after graduation was a consideration when choosing to come to the U.S. for their education. But their understanding of work related immigration policies was minimal before they came to the U.S. Most seemed to believe that finding work in the U.S. after graduation would be much easier than it was in reality. They did not arrive in the U.S. with a plan to work, but they did assume that it would be an option for them after graduation. The students did not refer specifically to the OPT program or the two year extension as a motivating factor for them when considering the option to study in the U.S. While it may be a benefit, they either had not heard of the program or did not fully understand it before they arrived. The program did provide them with the option to start their career in the U.S. instead of their home country, but utilizing this particular program was not planned in advance. 
This might be attributable to the fact that the OPT program was traditionally a one year, temporary work program that more closely resembled an internship. The two year STEM extension has shifted this perception for students in a STEM field, as a three year program has more value to an individual at the start of their career. The extension has only been offered since 2008 , and so its influence as a policy has only been recognized recently. As more students take advantage of the program, awareness of its importance is growing, and so could its influence on the career decisions of international students.

All of the students in the study were focused on the next step in their career, in one way or another - returning home, asking their employers to petition to get an $\mathrm{H} 1 \mathrm{~B}$ visa or green card, or finding some other path forward in their career. Their OPT position was only a stepping-stone, although a potentially important one. Even though the students have the possibility of working for three years with their current company, they are aware that another set of immigration obstacles awaits them. They recognize that these obstacles must be addressed immediately if they hope to continue on their current career path. This is quite different from a student without any immigration barriers who can enter their first job with the possibility of remaining with that company indefinitely, or with the option to switch positions without immigration concerns. The data collected shows that the temporary nature of OPT forces these students to be flexible with their career choices, and this can cause additional anxiety about their future career path.

The findings support the concept that a student's ability to build social capital does help them to further their careers. Students who specifically mentioned their faculty advisor or mentor generally spoke about the ability (or sometimes inability) of this individual to connect them with job opportunities. The network that these students 
develop at the university, whether it was through their academic department, the international affairs office, career services, or an additional opportunity at the university, such as a teaching or research assistantship, helped them to function in a U.S. work environment. The network they had built assisted them when navigating the job search process, and helped them to learn how to communicate effectively enough with their American colleagues to be successful in their positions. These students seemed to recognize intuitively that they had limited social capital, even if they did not utilize this terminology, and that they needed to build this capital in order to launch their careers successfully. They spoke of their need to work harder and place pressure on themselves to prove their value. They were aware that they did not always fit in, but they were determined to find connections that would ensure their success.

The study also provides strong support for a Social Cognitive Career Theory interpretation of the student's experience. As mentioned in the literature review, this theory places a significant emphasis on an individual's ability to be aware of the many influences on career choices and opportunities, both internal and external. These students must recognize their individual strengths and weaknesses, as well as the limitations placed on them by their temporary visa status. Juggling these influences to find a way forward in one's career was a dominant theme in the data collected. The students frequently looked for an attainable start to their career, and were looking for an attainable way to continue their career. They adjusted their goals and expectations based upon the realities of immigration policies, as well as their belief in themselves and the skills that they possess. This outlook ties neatly into the Social Cognitive Career Theory 
perspective, where individuals make career decisions based both on their own skill set and on outside influences.

\section{Limitations of the study}

The small number of students interviewed was a significant limitation to the study. As noted earlier, there were no female students interviewed, and the students only represented five countries. This sample, therefore, prevents the conclusions from being presented as representative of the entire population of international students. In addition, the participants only attended two schools located in the Midwest, and the results could vary if students from different schools in different areas of the country were included.

Another limitation is the method by which students were selected to be

interviewed. The students were asked to volunteer for the study with no compensation or incentives offered. It is likely that only specific types of students would be willing to participate. One could speculate that those willing to volunteer for the study would be more likely to be satisfied with their current position than not. Those experiencing difficulties in the workplace may be less likely to want to discuss their situation in an interview. Others may have been motivated to participate in the study out of a feeling of obligation to their university or the international office that helped them navigate the requirements of securing an OPT position. Those who did not get the assistance needed may be less likely to agree to be interviewed. The factors that motivated these students to participate may show up in the data, such as in the positive responses provided about the international office and the workplace environment. Therefore, the validity of the data is somewhat compromised by the fact that the participants were self-selected. 
Furthermore, in order to gain a full understanding of the issues surrounding the career related decisions of international students, it would be important to hear the voices of students who were unable to secure an OPT position or those who chose not to participate in the program. Having the opinions of these groups of students would be extremely valuable for purpose of comparing their perceptions with those who were successful in securing an OPT position.

Although the researcher made every effort to gain the trust of the students during the interview, some participants may have been concerned enough by their immigration status that they did not fully reveal their opinions about the program, their employer, or their university. Several of the students acknowledged their concerns about current events, in particular the travel ban proposed for individuals from specific countries which was under legal consideration at the time of the interviews. The students spoke cautiously about this situation, and their concerns may have impacted their ability to trust the researcher.

\section{Recommendations and Implications}

Universities wishing to assist international students in their transition to work can learn from the perceptions presented in this study. First, the study indicated that faculty members are a primary source of information about employment for these students. As the Council of Graduate Schools Pathway's report pointed out, faculty members tend to be more aware of teaching and research career paths than those that exist outside of academia. (CGS, 2012) If universities could find ways to encourage their faculty members to develop closer ties with employers, this could potentially assist the students as they begin of their careers. Whether this is done by promoting joint research projects 
or sponsoring collaborative events, creating these links is likely have a positive impact on students over time. The faculty will be more aware of the needs of the business community and have personal connections and insight that they can pass on to their students.

Faculty members are not the only sources of information, however. Career centers and other campus support offices also have a role to play. These offices can help educate employers about the OPT program and regulations relating to hiring international students. They can also actively attempt to identify employers who are willing to hire international students on OPT and connect them with interested students. Finding more ways to help these students connect with prospective employers was the most frequently mentioned request that participants had of their university. In addition, by understanding the concerns that employers have when hiring these students, these offices can help establish better expectations for both groups.

International students who arrive on a college campus for one or two years in a Master's program often must overcome many acculturation issues in a very short period of time. Several students mentioned that some services offered by the university, such as resume writing or interviewing skills seminars, were not offered frequently enough for them to find time to participate, or these seminars did not go into enough detail to be valuable. By coordinating services at times that are more convenient to graduate students, and by reaching out to these students earlier in their educational careers, universities may be better able to provide these students with the tools needed to find a job and be successful. 
Students felt that the technical education they received from their university was excellent, but many of them suggested more practical activities should be incorporated into the curriculum. They talked about the need for coursework in project management, field trips to local manufacturing facilities, and better instructions on how to write reports and research. Obviously the required curriculum in a STEM master's degree is necessarily heavy on technical training, but finding ways to incorporate more of the practical skills that these students have identified as important to their career could strengthen the overall value of the degree.

From the perspective of immigration policy, it is important to remember that the original OPT program was intended to give international students the opportunity for a short (one year), internship-type of work experience. The OPT extension was implemented to assist American companies who could not find qualified candidates to meet their workforce needs. When updating the OPT rules in 2016, the U.S. Department of Homeland Security highlighted the need to keep more of these students in the U.S. for the benefit of employers, the economy and "the nation's economic, scientific, and technological competitiveness" (Federal Registrar, 2016, p. 13043). The two-year extension for students with a STEM degree did what it was intended to do, supplement the H1B visa program as a source of highly skilled labor for high tech employers. At the same time, it created a new option for international students at the beginning of their career. As long as the continuation of this program appears in doubt, however, students will likely consider this option to be tenuous, and they will continue to look for other opportunities to start their career. If the U.S. hopes to use the OPT program as a way to attract and retain these highly skilled and educated individuals, students must believe that 
the rules are unlikely to change and that the program will continue. Otherwise, these U.S. educated students will continue to consider their career options in other countries.

The debate over immigration has many facets, and any program that provides a pathway for non-citizens to remain in the country is likely to be controversial. This study was not intended to determine if such a program is in the best interests of the country, but rather to examine the impact of the program on those who choose to participate in it. While the limitations of the OPT program cause some problems and perhaps a degree of anxiety for the students, the opportunities it creates at the start of their careers is undeniable. If the opportunity for three years of OPT becomes reliable for international students, it will likely play a key role in the career decision-making process of many more international students in the future.

\section{Suggestions for further study}

In order to be able to understand the role of OPT fully, similar studies that involve a broader mix of international students must be conducted. In particular, it is important to determine if female students have a different view of the OPT program and the opportunities that it provides to them. Understanding their experience in the workplace is critically important. Having a larger sample size will also help to determine if students from different countries and cultures have different experiences and perceptions.

Delving deeper into how social cognitive theory relates to international students in their career decision-making process could be extremely valuable for career counselors. Career guidance for international students is becoming more important at U.S. universities, and further research could help develop models that are applicable to this population of students. The social cognitive theory of career development framed the 
stories of these students in a striking manner, and utilizing this theory could guide interesting and insightful possibilities for further research.

Finally, conducting research to learn about the perspective of employers who hire international students would complement the findings from this study. Understanding how employers perceive the strengths and weaknesses of the international students that they hire would be of great benefit to universities as they work to strengthen their programs and prepare these students. In addition, a better understanding of the difficulties that employers experience when dealing with the OPT program, and other work related immigration policies, would allow professionals working in university career services and international affairs offices to provide better advice to international students as they seek to begin their professional career.

This study has demonstrated that each international student has an individual story to share. Their career paths are varied, and they bring unique talents and perspectives to both the classroom and the workplace. To generalize their expectations and plans for the future would be a mistake. However, attempts to understand how these students perceive their experiences, and efforts to recognize their hopes and career aspirations can be instrumental to the development of sound immigration policies and institutional practices. 


\section{Appendix A - Interview protocol}

1. Please tell me a little about yourself - where you are from, what you majored in, and how you got this OPT position.

2. What do you like most about your position? And what do you find the most challenging?

3. How well do you think that the university prepared you for this position - both in terms of your technical skills and your ability to contribute to the workplace environment?

4. Was there any person, office or service at the university that was particularly helpful to you in your efforts to secure an OPT position? What did they do and how did it help you?

5. Can you give an example of a challenge that you have faced relating to your OPT position and what would have helped better prepare you for this challenge?

6. Why did you choose to participate in OPT?

7. Were you planning to work in the United States after graduation when you began your studies? If not, what changed your mind?

8. Now that you are on OPT, how has your understanding of work related immigration policies changed from when you first arrived in the U.S.?

9. Do you hope to remain in the U.S. to continue your career after your OPT is complete, or do you plan to return to your home country? Why?

10. Can you give an example of something valuable that you have learned while on OPT and how do you think this lesson will help you in your career in the U.S. or your home country? 
11. What advice would you give to individuals from your country who are beginning their studies in the U.S. and may wish to seek out employment or an OPT position in the U.S.?

12. Is there anything else that you can think of that would have made the transition from your academic studies to employment easier? 


\section{Appendix B - Complete Table 1 with Individual Student Responses}

Table 1: Themes and ideas found in the data

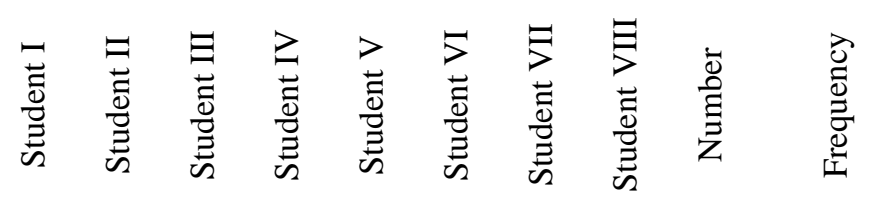

Theme
Opportunities

Idea

Work experience

Practical skills

acquisition

Technical knowledge

enhancement

Networking

Money/Financial

Critical to education

\begin{tabular}{|c|c|c|c|c|c|c|c|c|c|}
\hline $\mathrm{X}$ & $\mathrm{x}$ & $\mathrm{X}$ & $\mathrm{X}$ & $\mathrm{x}$ & $\mathrm{X}$ & $\mathrm{x}$ & $\mathrm{x}$ & 8 & Common \\
\hline $\mathrm{x}$ & $\mathrm{x}$ & $\mathrm{X}$ & $\mathrm{x}$ & $\mathrm{x}$ & $\mathrm{x}$ & $\mathrm{x}$ & & 7 & Common \\
\hline $\mathrm{X}$ & $\mathrm{x}$ & $\mathrm{X}$ & $\mathrm{x}$ & $\mathrm{x}$ & $\mathrm{x}$ & & & 6 & Typical \\
\hline \multirow[t]{4}{*}{$\mathrm{X}$} & $\mathrm{x}$ & $\mathrm{x}$ & $\mathrm{x}$ & & & $\mathrm{x}$ & $\mathrm{x}$ & 6 & Typical \\
\hline & $\mathrm{x}$ & $\mathrm{X}$ & $\mathrm{x}$ & $\mathrm{x}$ & & & & 4 & Variant \\
\hline & & $\mathrm{X}$ & $\mathrm{x}$ & & & $\mathrm{x}$ & $\mathrm{x}$ & 4 & Variant \\
\hline & $\mathrm{X}$ & & $X$ & & & & $\mathrm{X}$ & 3 & Variant \\
\hline
\end{tabular}

Regulation

Demonstrate

achievement

Issues

University

Complicated to

understand

Uncertainty

Limits Options

Causes confusion

Causes anxiety

$\begin{array}{cccccccccc}\mathrm{x} & \mathrm{x} & \mathrm{x} & \mathrm{x} & \mathrm{x} & \mathrm{x} & \mathrm{x} & \mathrm{x} & 8 & \text { Common } \\ \mathrm{x} & \mathrm{x} & \mathrm{x} & \mathrm{x} & \mathrm{x} & & \mathrm{x} & & 6 & \text { Typical } \\ & \mathrm{x} & \mathrm{x} & \mathrm{x} & & \mathrm{x} & \mathrm{x} & \mathrm{x} & 6 & \text { Typical } \\ \mathrm{x} & \mathrm{x} & \mathrm{x} & & & & \mathrm{x} & \mathrm{x} & 5 & \text { Typical } \\ \mathrm{x} & & & & & & \mathrm{x} & \mathrm{x} & 3 & \text { Variant }\end{array}$

Role

Technical knowledge acquisition

Extra opportunities for learning

Explained rules

$\begin{array}{lll}\mathrm{X} & \mathrm{X} & \\ \mathrm{X} & \mathrm{X} & \mathrm{X}\end{array}$

X $\quad$ X $\quad$ X

Faculty advisors /

mentors

Career services

Importance of

practical coursework

Encouragement

Assistance lacking or

problematic

$\begin{array}{lllllllllll}\mathrm{X} & \mathrm{X} & \mathrm{X} & \mathrm{X} & \mathrm{X} & \mathrm{x} & \mathrm{x} & \mathrm{x} & 8 & \text { Common }\end{array}$

Need for links to

employers

$\mathrm{X}$

$\mathrm{X}$

X $\quad$ X $3 \quad$ Variant

$\mathrm{X}$

$\mathrm{x}-\mathrm{x}$

X 4 Variant

$\mathrm{X}$

$\mathrm{X}$

$\mathrm{X} \quad \mathrm{X} \quad \mathrm{X}$

X 4 Variant

3 Variant 
Table 1. (Continued)

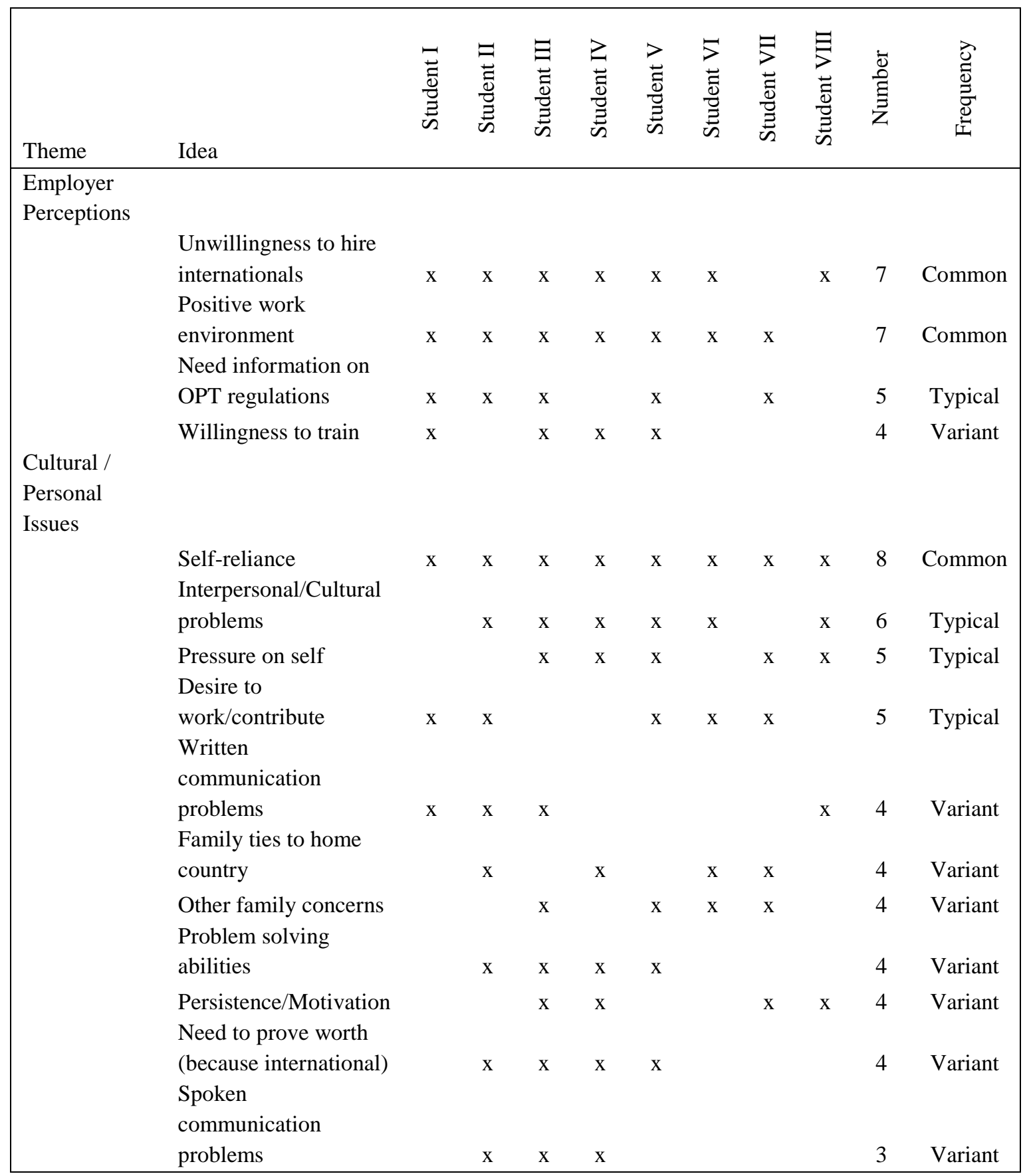




\section{Appendix C - IRB Approval}

\section{반}

Institutional Review Board

University of Missouri-Columbia
190 Galena Hall: Dc071.00

Columbia, MO 65212

$573-8322-3181$

irb@missouri.edu

Septenber 21, 2017

Principal Investigator: James L Monahan, EdD Educational Leadership and Policy Mnalysis Department: Education

Your Exempt $A m e n d m e n t$ Form to project entitled International Student. Perceptions on the Optional Practical Training Experience was reviewed and approved by the MU Institutional Review Board according to the terms and conditions described below:

\begin{tabular}{|c|c|}
\hline IRB Project Number & 2008110 \\
\hline IRB Review Number & $2: 30103$ \\
\hline \multicolumn{2}{|c|}{ Initial Application $A$ pproval Date June 16, 2017} \\
\hline Approval Date of this Review & September 21, 2017 \\
\hline IRB Expiration Date & June 16,2018 \\
\hline Level of Review & Exempt \\
\hline Project. Status & $\begin{array}{l}\text { Active - Open to } \\
\text { Enrollment }\end{array}$ \\
\hline Risk Level & Minimal Risk \\
\hline
\end{tabular}

The principal investigator (PI) is responsible for all aspects and conduct of this study. The PI nust comply with the following conditions of the approval:

1. No subjects may be involved in any study procedure prior to the IRB approval date or after the expiration date.

2. All unanticipated problems and deviations must be reported to the IRB within 5 business days.

3. All changes must be IRB approved prior to implementation unless they are intended to reduce inmediate risk.

1. All recruitment materials and methods must be approved by the IRB prior to being used.

5. The Annual Exempt. Form nust be submitted to the IRB for review and approval at least 30 days prior to the project expiration date. If the study is complete, the Completion/withdrawal Form may be submitted in lieu of the $A$ mnual Exempt. Form

6. Maintain all research records for a period of seven years from the project completion date.

7. Utilize all approved research documents located within the attached files section of eCompliance. These documents are highlighted green.

If you are offering subject payments and would like more information about research 
participant payments, please click here to view the MU Business Policy and Procedure: http://bppm.missouri.edu/chapter2/2_250.html

If you have any questions, please contact the IRB at 573-882-3181 or irb@missouri.edu.

Thank you,

MU Institutional Review Board 


\section{References}

Andrade, M.S. (2006). International students in English-speaking universities: Adjustment factors. Journal of Research in International Education, 5(2), 131-154.

Arthur, N., \& Flynn, S. (2011). Career development influences of international students who pursue permanent immigration to Canada. International Journal for Educational and Vocational Guidance, 11(3), 221-237. Retrieved from http://search.proquest.com/docview/964174428?accountid=14576

Arthur, N., \& Popadiuk, N. (2010). A cultural formulation approach to career counseling with international students. Journal of Career Development, 37(1), 423-440. Doi: $10.1177 / 0894845309345845$.

Barnes, B., Williams, E., \& Stassen, M.L.A. (2014). Dissecting doctoral advising: a comparison of students' experiences across disciplines. Journal of Further and Higher Education, 36(3), 309-331. Doi: 10.1080/0309877x.2011.614933.

Bikos, L.H., \& Furry, T.S. (1999). The job search club for international students: An evaluation. The Career Development Quarterly, 48 (1), 31-44.

Charles, H., \& Stewart, M. A. (1991). Academic Advising of international students. Journal of Multicultural Counseling \& Development, 19(4), 173-181.

Clifton, R.A. (1999). The education of university students: A social capital perspective. College Teaching, 47(3), 114-118.

Crockett, S. A., \& Hays, D. G. (2011). Understanding and responding to the career counseling needs of international college students on U.S. campuses. Journal of College Counseling, 14, 65-79. doi: 10.1002/j.2161-1882.2011.tb00064.x 
Crose, B. (2011). Internationalization of the higher education classroom: Strategies to facilitate intercultural learning and academic success. International Journal of Teaching and Learning in Higher Education, 23(3), 388-395. Retrieved from http://search.proquest.com/docview/964178531 accountid=14576

Council of Graduate Schools and Educational Testing Service (2012). Pathways through Graduate School and into Careers. Report from the Commission on Pathways through Graduate School and into Careers. Retrieved from http://pathwaysreport.org/

Dika, S., \& Singh, K. (2002). Applications of social capital in educational literature: A critical synthesis. Review of Educational Research, 72(1), 31-60.

Federal Register (2016). Improving and Expanding Training Opportunities for F-1 Nonimmigrant Students with STEM Degrees and Cap-Gap Relief for All Eligible F-1 Students. Retrieved from https://www.federalregister.gov/documents/2016/03/11/2016-04828/improving-andexpanding-training-opportunities-for-f-1-nonimmigrant-students-with-stem-degreesand

Fowler, P. R., \& Boylan, H. R. (2010). Increasing student success and retention: A multidimensional approach. Journal of Developmental Education, 34(2), 2-4. Retrieved from http://search.proquest.com/docview/1312421349?accountid=14576

Frost, S.H. (2000). Historical and philosophical foundations for academic advising. In Gordon, V.N., Habley, W.R., \& Associates (Eds.), Academic advising: A comprehensive handbook (pp. 3-17). San Francisco: Jossey-Bass. 
Gibson, E. (2005). The development of career services for international students. Australian Journal of Career Development, 14(2), 19-23. doi:10.2255/10384162.14.2.0022

Leung, S. Alvin (2008). The big five career theories. In Athanasou, J.A. \& Van Esbroeck, R. (Eds.), International handbook of career guidance (pp. 115-132). Springer.

Habley, W.R. (2000). Current practices in academic advising. In Gordon, V.N., Habley, W.R., \& Associates (Eds.), Academic advising: A comprehensive handbook (pp. 3543). San Francisco: Jossey-Bass.

Hill, C. E., Knox, S., Thompson, B. J., Williams, E. N., Hess, S. A., \& Ladany, N. (2005). Consensual qualitative research: An update. Journal of Counseling Psychology, 52(2), 196-205. Retrieved from http://search.proquest.com/docview/62137596?accountid=14576

Holmes, P. (1997). Future directions in international science education. Frontiers: The Interdisciplinary Journal of Study Abroad, 3(2), 233-239. Retrieved from http://search.proquest.com/docview/62374864?accountid=14576

Institute of International Education. (2016). Open Doors Data [Data set]. Retrieved from http://www.iie.org/Research-and-Publications/Open-Doors/Data\#.WM8fCKLauUk .

Kato, T., \& Sparber, C. (2013). Quotas and quality: The effect of H-1B visa restrictions on the pool of prospective undergraduate students from abroad. The Review of Economics and Statistics, 95(1), 109-126.

Kim, J. (2007). Difficulties in quality doctoral academic advising. Journal of Research in International Education 6(2), 171-193. Doi:10.1177/147524090707.8613. 
Kim, J. (2012). The birth of academic subalterns: How do foreign students embody the global hegemony of American universities? Journal of Studies in International Education, 16(5), 455-476. doi:10.1 177/10283.53.407510

Knox, S., Schlosser, L. Z., Pruitt, N. T., \& Hill, C. E. (2006). A qualitative examination of graduate advising relationships: The advisor perspective. Counseling Psychologist, 34(4), 489-518. doi:http://dx.doi.org/10.1177/0011000006290249

Knox, S., Sokol, J. T., Inman, A. G., Schlosser, L. Z., Nilsson, J., \& Wang, Y. (2013). International advisees' perspectives on the advising relationship in counseling psychology doctoral programs. International Perspectives in Psychology: Research, Practice, Consultation, 2(1), 45-61. doi:10.1037/ipp0000001

Krauss, S. E., \& Ismail, I. A. (2010). PhD students' experiences of thesis supervision in Malaysia: Managing relationships in the midst of institutional change. Qualitative Report, 15(4), 802-822. Retrieved from http://search.proquest.com/docview/757167180?accountid=14576

Lawrence, J. H., Celis, S., Kim, H. S., Lipson, S. K., \& Tong, X. (2014). To stay or not to stay: Retention of asian international faculty in STEM fields. Higher Education, 67(5), 511-531. doi:10.1007/s10734-013-9658-0

Lent, R. W., Hackett, G., \& Brown, S. D. (1999). A social cognitive view of school-towork transition. The Career Development Quarterly, 47(4), 297-311. Retrieved from http://search.proquest.com/docview/219438652?accountid=14576

Lin, Y., \& Flores, L. Y. (2013). Job search self-efficacy of east asian international graduate students. Journal of Career Development, 40(3), 186-202. Retrieved from http://search.proquest.com/docview/1413416429?accountid=14576 
Leung, S. Alvin (2008). The big five career theories. In Athanasou, J.A. \& Van Esbroeck, R. (Eds.), International handbook of career guidance (pp. 115-132). Springer.

Lynette, H. B., \& Tinsley, S. F. (1999). The job search club for international students: An evaluation. The Career Development Quarterly, 48(1), 31-44. Retrieved from http://search.proquest.com/docview/219385207?accountid=14576

McGillin, V. (2000). Current issues in advising research. In Gordon, V.N., Habley, W.R., \& Associates (Eds.), Academic advising: A comprehensive handbook. San Francisco: Jossey-Bass.

Musumba, M., Jin, Y. H., \& Mjelde, J. W. (2011). Factors influencing career location preferences of international graduate students in the United States. Education Economics, 19(5), 501-517. doi:10.1080/09645290903102902

NAFSA. (2016) Focus on STEM OPT. Retrieved from http://www.nafsa.org/Professional_Resources/Browse_by_Interest/International_Stud ents_and_Scholars/Focus_On_STEM_OPT/.

NAFSA. (2016). STEM OPT rulemaking. Retrieved from http://www.nafsa.org/Professional_Resources/Browse_by_Interest/International_Stud ents_and_Scholars/STEM_OPT_Rulemaking/.

National Foundation for American Policy. (2013, July). The importance of international students to America (Issue Brief). Arlington, VA. Retrieved from http://nfap.com/research-2/study-by-year/.

National Science Foundation. (2016). Survey of graduate students and postdoctorates in science and engineering, fall 2015 [Data Tables]. Retrieved from http://www.nsf.gov/statistics/srvygradpostdoc/\#tabs-2. 
Novera, I. A. (2004). Indonesian postgraduate students studying in Australia: An examination of their academic, social and cultural experiences. International Education Journal, 5(4), 475-487. Retrieved from http://search.proquest.com/docview/815956536? accountid=14576

Okahana, H., Feaster, K. and Allum, J. (2016). Graduate enrollment and degrees: 2005 to 2015. Washington, DC: Council of Graduate Schools. Retrieved from http://cgsnet.org/graduate-enrollment-and-degrees

Pankhurst, V. K. (2010). Learning by experience, work and productivity: Theory and empirical evidence. Journal of Vocational Education and Training, 62(2), 103-122. Retrieved from http://search.proquest.com/docview/754908711?accountid=14576

Park-Saltzman, J., Wada, K., \& Mogami, T. (2012). Culturally sensitive mentoring for asian international students in counseling psychology. Counseling Psychologist, 40(6), 895-915. Retrieved from http://search.proquest.com/docview/1312422611 ?accountid=14576

Popadiuk, N.E. \& Arthur, N.M. (2014). Key Relationships for International student university-to-work transitions. Journal of Career Development, 41(2), 122-140.

Poyrazli, S., \& Kavanaugh, P.R. (2006). Marital status, ethnicity, academic achievement, and adjustment strains: The case of graduate international students. College Student Journal 40(4), 767-780.

Punyanunt-Carter, N., \& Wrench, J. S. (2008). Advisor-advisee three: Graduate students' perceptions of verbal aggression, credibility, and conflict styles in the advising relationship. Education, 128(4), 579-587. Retrieved from http://search.proquest.com/docview/61950394?accountid=14576 
Rae, D., \& Woodier-Harris, N. (2012). International entrepreneurship education: Postgraduate business student experiences of entrepreneurship education. Education \& Training, 54(8), 18. Retrieved from http://search.proquest.com/docview/1312420998?accountid=14576

Rice, K. G., Choi, C., Zhang, Y., Villegas, J., Ye, H., Anderson, D., \& Bigler, M. (2009). International student perspectives on graduate advising relationships. Journal of Counseling Psychology, 56(3), 376-391. doi:10.1037/a0015905

Reynolds, A.L. \& Constantine, M.G. (2007). Cultural adjustment difficulties and career development of international college students. Journal of Career Assessment, 15 (3), 338-350.

Sangganjanavanich, V. F., Lenz, A. S., \& Cavazos, J.,Jr. (2011). International students' employment search in the United States: A phenomenological study. Journal of Employment Counseling, 48(1), 17-26. Retrieved from http://search.proquest.com/docview/862561749?accountid=14576

Schlosser, L. Z., \& Gelso, C. J. (2005). The advisory working alliance inventory--advisor version: Scale development and validation. Journal of Counseling Psychology, 52(4), 650-654. Retrieved from http://search.proquest.com/docview/62088569?accountid=14576

Schlosser, L. Z., Lyons, H. Z., Talleyrand, R. M., Kim, B. S., \& Johnson, B. W. (2011). Advisor-advisee relationships in graduate training programs. Journal of Career Development, 38(1), 3-18. Retrieved from http://search.proquest.com/docview/860367128?accountid=14576 
Schlosser, L. Z., Talleyrand, R. M., Lyons, H. Z., Kim, B. S., \& Johnson, B. W. (2011). Multicultural issues in graduate advising relationships. Journal of Career Development, 38(1), 19-43. Retrieved from http://search.proquest.com/docview/864938902?accountid=14576

Schlosser, L. Z., Lyons, H. Z., Talleyrand, R. M., Kim, B. S. K., \& Johnson, W. B. (2011). A multi-culturally infused model of graduate advising relationships. Journal of Career Development, 38(1), 44-61. doi:10.1177/0894845309359286

Schwartz, H. L. (2011). From the classroom to the coffee shop: Graduate students and professors effectively navigate interpersonal boundaries. International Journal of Teaching and Learning in Higher Education, 23(3), 363-372. Retrieved from http://search.proquest.com/docview/964178718?accountid=14576

Scott, T. P., \& Tolson, H. (2009). Predicting retention of mathematics and science majors at a research one institution and suggested advising tools. Journal of College Admission, (204), 20-24. Retrieved from http://search.proquest.com/docview/61827808?accountid=14576

Shen, Y., \& Herr, E. L. (2004). Career placement concerns of international graduate students: A qualitative study. Journal of Career Development, 31(1), 15-29. Retrieved from http://search.proquest.com/docview/220425149?accountid=14576

Singaravelu, H. D., White, L. J., \& Bringaze, T. B. (2005). Factors influencing international students' career choice: A comparative study. Journal of Career Development, 32(1), 46-59. Retrieved from http://search.proquest.com/docview/61907027?accountid=14576 
Stoynoff, S. (1996). Self-regulated learning strategies of international students: A study of high- and low-achievers. College Student Journal, 30(3), 329.

Stoynoff, S. (1997). Factors associated with international students' academic achievement. Journal Of Instructional Psychology, 24(1), 56-68.

Sumer, S. (2009). International students' psychological and sociocultural adaptation in the United States. (Order No. 3401617, Georgia State University). ProQuest Dissertations and Theses, 75-n/a. Retrieved from http://search.proquest.com/docview/304891980?accountid=14576. (304891980).

Trice, A.G. (2004). Mixing it up: International graduate students' social interactions with American students. Journal of College Student Development, 45(6), 671-687. Doi:10.1353/csd.2004.0074.

Trice, A.G., \& Yoo, J.E. (2007). International graduate students' perceptions of their academic experience. Journal of Research in International Education, 6(1), 41-66.

U.S. Citizenship and Immigration Services Practical Training (2016). Student and exchange visitor program practical training. Retrieved from https://www.ice.gov/sevis/practical-training

U.S. Citizenship and Immigration Services I-9 Central (2016) Foreign students. Retrieved from https://www.uscis.gov/i-9-central/complete-correct-form-i9/complete-section-1-employee-information-and-attestation/foreign-students

U.S. Citizenship and Immigration Services Laws (2016). Title 8 of the code of federal regulations: Department of homeland security nonimmigrant classes, 8 C.F.R. $\S$ 214.2. Retrieved from https://www.uscis.gov/laws/8-cfr/title-8-code-federalregulations. 
U.S. Citizenship and Immigration Services Visa Guide (2016). Understanding F-1 optional practical training $(O P T)$ requirements [Online reference guide]. Retrieved from http://www.uscis.gov/eir/visa-guide/f-1-opt-optional-practicaltraining/understanding-f-1-opt-requirements

U.S. Visas (2016). U.S. department of state bureau of consular affairs: Directory of visa categories. [Data set] Retrieved from https://travel.state.gov/content/visas/en/general/all-visa-categories.html

Zelmer, A. E., \& Johnson, N. A. (1988). International students in higher education: A follow-up study of university graduates. Canadian Journal of Higher Education, 18(3), 31-50. Retrieved from http://search.proquest.com/docview/63119248?accountid=14576 


\section{VITA}

James Monahan worked at St. Louis Community College for ten years, where he become involved in a program that brought international students to community college campuses across the country. Through Community Colleges for International Development (CCID), he assisted groups of international students who came to St. Louis for a one-year study program. By helping these students, learning from them, and making some mistakes along the way, he began to understand the various challenges international students face. He also quickly recognized the incredible opportunity for learning that student mobility programs provide, not only to participating students but also to the campus as a whole.

As the Associate Director of International Affairs at Missouri University of Science and Technology, he was able to travel widely to recruit students interested in coming to the U.S. for their education. He promoted efforts to internationalize the campus and worked to build partnerships with universities in numerous countries. It was in this position that the OPT program became the topic for his dissertation.

Currently, he serves as the Director of Graduate and International Admissions at Southern Illinois University Edwardsville, where he has the opportunity to lead the university's international student recruitment efforts and collaborate with campus leaders to build international programs. 